\title{
A Comparison of the Gas Phase Acidities of Phospholipid Headgroups: Experimental and Computational Studies
}

\author{
Michael C. Thomas, Todd W. Mitchell, and Stephen J. Blanksby \\ Department of Chemistry, University of Wollongong, Wollongong, New South Wales, Australia
}

Proton-bound dimers consisting of two glycerophospholipids with different headgroups were prepared using negative ion electrospray ionization and dissociated in a triple quadrupole mass spectrometer. Analysis of the tandem mass spectra of the dimers using the kinetic method provides, for the first time, an order of acidity for the phospholipid classes in the gas phase of PE $<$ PA $\ll$ PG $<$ PS $<$ PI. Hybrid density functional calculations on model phospholipids were used to predict the absolute deprotonation enthalpies of the phospholipid classes from isodesmic proton transfer reactions with phosphoric acid. The computational data largely support the experimental acidity trend, with the exception of the relative acidity ranking of the two most acidic phospholipid species. Possible causes of the discrepancy between experiment and theory are discussed and the experimental trend is recommended. The sequence of gas phase acidities for the phospholipid headgroups is found to (1) have little correlation with the relative ionization efficiencies of the phospholipid classes observed in the negative ion electrospray process, and (2) correlate well with fragmentation trends observed upon collisional activation of phospholipid $[\mathrm{M}-\mathrm{H}]^{-}$anions. (J Am Soc Mass Spectrom 2005, 16, 926-939) @ 2005 American Society for Mass Spectrometry

$\mathrm{G}$ lycerophospholipids form the key structural component of biological cell membranes. These membranes not only separate the cell from the external environment but also form organelles within the cell providing specialized environments for many specific biochemical processes [1]. The general molecular structure of glycerophospholipids consists of a glycerol backbone bound via ester linkages to two fatty acids and a phosphate moiety (Figure 1). There are several phospholipid classes that differ in the substituent, or headgroup, linked to the phosphate that provides characteristic physical and chemical properties. The phospholipid classes are known to distribute heterogeneously between cell types and even within individual cells suggesting that they have distinct biological roles. Studies of human erythrocyte membranes have shown that the outer leaflet contains predominantly phosphatidylcholine (PC) while the inner leaflet is enriched in phosphatidylethanolamines (PE) and phosphatidylserines (PS) [2]. In addition to their structural role in membranes, phospholipids are involved in a range of cell biochemistries including cell signaling and oxidative processes $[1,3]$. For example, phosphatidylinisitol (PI) has been shown to be an important precursor for cell signaling molecules [4].

Published online April 26, 2005

Address reprint requests to Dr. S. J. Blanksby, Department of Chemistry, University of Wollongong, Northfields Road, Wollongong, NSW 2522, Australia. E-mail: blanksby@uow.edu.au
Understanding the role of phospholipids in determining the physical and chemical properties of cells requires the ability to identify and quantify changes in phospholipid speciation between different cells, different organelles, or even different domains within the same membrane, as is the case for the recent interest in lipid rafts $[5,6]$.

Electrospray ionization mass spectrometry (ESI-MS) has emerged over the last ten years as the most efficient methodology for lipidomic analysis and has dramatically accelerated progress in the field [7-9]. Negative ion electrospray mass spectrometry, in particular, has been shown to be a powerful method for the detection of acidic phospholipids in complex lipid extracts. While absolute quantitation of these species continues to require laborious separation procedures, comparison of ESI-MS lipid profiles of crude lipid extracts is gaining popularity as a means to rapidly identify relative differences in phospholipid composition between samples $[7,10]$. This methodology has recently been dubbed "shotgun lipidomics" [9]. While such experiments are extremely useful in highlighting gross differences in lipid profiles, their usefulness for quantitation can be limited by the differing ionization efficiencies of the phospholipid headgroups. For example, the signal observed for neutral phosphatidylethanolamines in the negative ion electrospray of a phospholipid extract is typically low compared with acidic phospholipids. The detection of $\mathrm{PE}$ is enhanced, however, if the $\mathrm{pH}$ is increased, usually via the addition of lithium or ammo- 

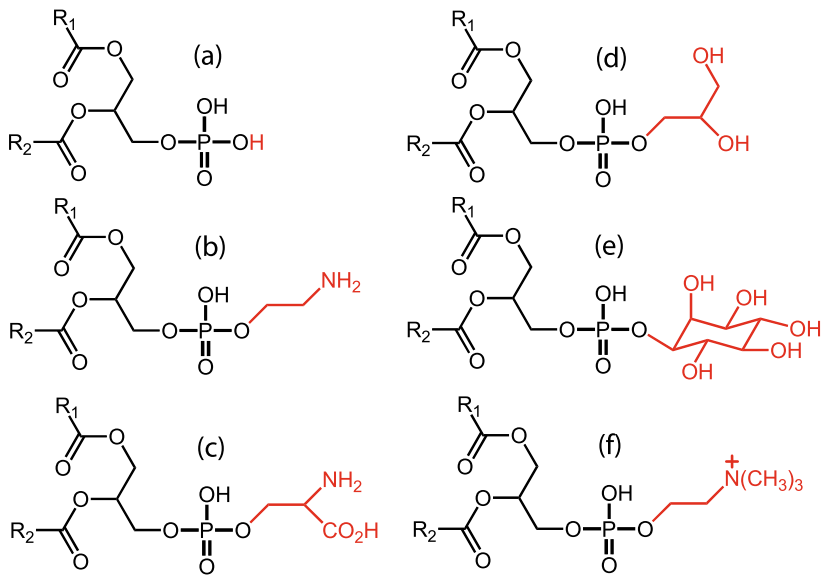

Figure 1. Structures of glycerophospholipids (a) phosphatidic acid (PA), (b) phosphatidylethanolamine (PE), (c) phosphatidylserine (PS), (d) phosphatidylglycerol (PG), (e) phosphatidylinisitol $(\mathrm{PI})$, and (f) phosphatidylcholine (PC). $\mathrm{R}_{1}$ and $\mathrm{R}_{2}$ are fatty acid alkyl chains.

nium hydroxide. As a consequence, this $\mathrm{pH}$ adjustment is now incorporated into some standard lipidomic analysis procedures such as that of Han and Gross [8, 9]. More subtle differences in ionization efficiency, however, have also been reported. Koivusalo et al. report the negative ion ESI-MS analysis of solutions containing a range of dipalmitoyl phospholipids present in equimolar concentrations [11]. These spectra, carried out at different total phospholipid concentrations (6-60 $\mu \mathrm{M}$ total phospholipid), demonstrate differences in ion abundances between the different phospholipid classes. The typical order of anion abundances from these data is $\mathrm{PG}>\mathrm{PI}>\mathrm{PA} \cong \mathrm{PS}>\mathrm{PE} \cong[\mathrm{PC}+\mathrm{Cl}]$, although the relative abundances of $\mathrm{PA}$ and $\mathrm{PE}$ ions are dramatically altered by addition of ammonium hydroxide to give a revised abundance ranking of $\mathrm{PA} \cong \mathrm{PG}>\mathrm{PI}>\mathrm{PS}>\mathrm{PE}$ $>[\mathrm{PC}+\mathrm{Cl}]$. These data clearly demonstrate the variable ionization efficiencies of the different phospholipid headgroups in negative ion ESI-MS. Furthermore, Zacarias et al. have demonstrated that these effects do not scale linearly with total sample concentration, thus increasing the complexity of phospholipid quantitation by direct ESI-MS analysis of crude extracts [12]. The observation of $[\mathrm{M}-\mathrm{H}]^{-}$anions in the ESI-MS spectra of phospholipids is the result of deprotonation of the acidic phosphate moiety. Deprotonation may occur either (1) in the solution phase prior to ionization as would be suggested by the charge residue model for electrospray ionization or (2) during the transition from solution to the gas phase, more consistent with the ion evaporation ionization model [13]. The solution phase $\mathrm{pK}_{\mathrm{a}}$ values for the phospholipid headgroups suggest that all acidic phospholipids (i.e., excepting PE and PC) have a net charge of -1 at $\mathrm{pH}=7$ [14]. This suggests that solution phase acidity alone is insufficient to explain the observed differences in phospholipid ionization efficiencies in the electrospray process and other molecular properties such as surface activity and perhaps gas phase acidity may play a role.

The gas phase acidity of different phospholipid species, or conversely the gas phase basicity of the corresponding $[\mathrm{M}-\mathrm{H}]^{-}$anions, may also account for subtle differences observed in the fragmentation patterns of deprotonated phospholipids [15-18]. For example, low energy collision induced dissociation of [PE $\mathrm{H}^{-}$anions is known to proceed preferentially via loss of the fatty acyl chains as ketenes ( $\mathrm{R}^{\prime} \mathrm{CHCO}$ ) [16], while in contrast $[\mathrm{PI}-\mathrm{H}]^{-}$anions fragment preferentially via loss of the whole fatty acid $\left(\mathrm{R}^{\prime} \mathrm{CH}_{2} \mathrm{CO}_{2} \mathrm{H}\right)$ [15]. This observation is due, at least in part, to the availability of more acidic protons on the inisitol compared with the ethanolamine headgroup, but may also be attributed to the difference in gas phase basicity between the two phosphate anions [16].

The gas phase acidities of phospholipids, which may provide some rationale for the observed trends in their ionization efficiencies and fragmentation behaviors, are largely unknown. It might be assumed that the gas phase acidity of phospholipids are similar to phosphoric acid $\left(\Delta_{\text {acid }} H_{298}\left[\mathrm{H}_{3} \mathrm{PO}_{4}\right]=1383 \pm 21 \mathrm{~kJ} \mathrm{~mol}^{-1}\right.$ [19] but the effects of the various headgroups in stabilizing or destabilizing the phosphate anion, with respect to protonated forms, have not previously been assessed. In this study, we have measured the relative order of the gas phase acidities of phosphatidic acid (PA), phosphatidylethanolamine (PE), phosphatidylinisitol (PI), phosphatidylglycerol (PG) and phosphatidylserine (PS) via the kinetic method. The experimental study is complemented by quantum chemical calculations of simplified model systems.

\section{Experimental}

\section{Mass Spectrometry}

Phospholipids were obtained from Avanti Polar Lipids (Alabaster, AL), with the exception of $\mathrm{PE}(17$ : 0,17:0) which was obtained from Sigma-Aldrich (Castle Hill, Australia). All phospholipids were used without further purification. Equimolar solutions of each pair of phospholipids were prepared using methanol:chloroform (approximately 1:3 by volume) at a total phospholipid concentration of $80 \mu \mathrm{M}$. Mass spectra were obtained using a QuattroMicro triple quadrupole mass spectrometer (Waters, Manchester, UK). Spectra were obtained by infusion of the standard solution (10 $\mu \mathrm{M} / \mathrm{min})$, typical settings were cone voltage $60 \mathrm{~V}$, capillary voltage $4.5 \mathrm{kV}$, source temperature $80^{\circ} \mathrm{C}$. ESI-MS spectra were obtained by scanning Q1 while operating Q3 in $\mathrm{R}_{\mathrm{f}}$-only mode. Resolution for ESI-MS and ESI-MS/MS experiments was typically $0.7 \mathrm{Th}$ across the entire mass range. ESI-MS/MS spectra were obtained by mass-selecting the parent ion using Q1 and scanning for product ions using Q3. Argon was used as the collision gas at a pressure of $4 \times 10^{-3}$ Torr. The collision energy 


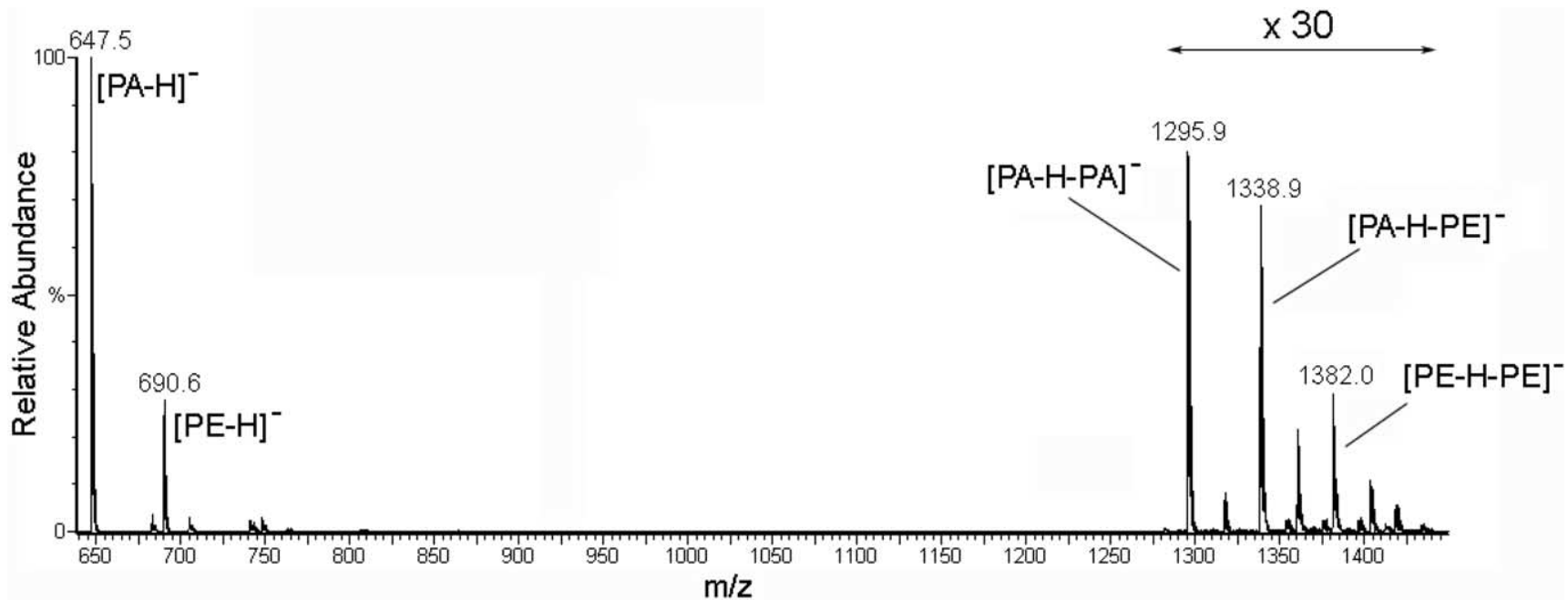

Figure 2. The negative ion ESI-MS spectrum obtained from an equimolar solution of PA(16:0,16:0) and $\mathrm{PE}(16: 0,16: 0)$ in methanol/chloroform (solvent ratio is 1:3) with a total phospholipid concentration of $80 \mu \mathrm{M}$. The minor peaks observed at $\mathrm{m} / \mathrm{z} 1317.9,1360.9$, and 1403.9 are due to sodium bound dimers.

dependence of fragmentation of a $[\mathrm{PA}(16: 0,16: 0)-\mathrm{H}-$ $\operatorname{PE}(16: 0,16: 0)]^{-}$dimer anion was investigated between 10 and $40 \mathrm{eV}$. A plot of the $[\mathrm{PE}(16: 0,16: 0)-\mathrm{H}]^{-} /$ $[\mathrm{PA}(16: 0,16: 0)-\mathrm{H}]^{-}$ratio against collision energy was found to have a slope of only -0.0001 indicating that the dimer fragmentation was largely independent of collision energy and a collision energy of $30 \mathrm{eV}$ was selected for all data presented here. ESI-MS and full scan ESI-MS/MS spectral data presented in this paper result from the average of at least 50 scans and zoom scan ESI-MS/MS spectra at least 300 scans. The data was baseline subtracted $(40 \%$ background subtract with a first order polynomial) and smoothed (two mean smooths using a peak width of $0.7 \mathrm{Th}$ ) and the ion abundances were determined by integration of the peaks using the MassLynx software (Waters, Manchester UK).

\section{Electronic Structure Methods}

Structures were optimized using the Becke3LYP hybrid density ${ }^{\circ}$ functional ${ }^{\circ}$ method ${ }^{\circ}[20,21]^{\circ}$ and $^{\circ}$ the ${ }^{\circ}$ modest ${ }^{\circ} 6-31$ $+\mathrm{G}(\mathrm{d})$ basis set within the Gaussian 03 suite of programs $^{\circ}[22] .{ }^{\circ}$ Stationary ${ }^{\circ}$ points $^{\circ}$ were $^{\circ}$ characterized $^{\circ}$ as minima (no imaginary frequencies) by calculation of analytical second derivatives. Single point energies for global minima were calculated with the extended 6-311 $++\mathrm{G}(\mathrm{d}, \mathrm{p})$ basis set and zero-point energies (ZPE), thermal corrections $\left(E^{298}\right)$ and a pressure-volume work term $(R T)$ were added, according to $H=\mathrm{E}^{0}+\mathrm{ZPE}+$ $\mathrm{E}^{298^{\circ}}+R T$ to $^{\circ}$ provide $^{\circ}$ an $^{\circ}$ enthalpy $^{\circ}(H)^{\circ}$ at $^{\circ} 298.15^{\circ} \mathrm{K}^{\circ}[23]$.

\section{Results and Discussion}

\section{Mass Spectrometry}

Noncovalent interactions between phospholipids have previously been observed in the gas phase by Robinson and coworkers who detected micelle-like assemblies of up to one hundred phospholipids from nanospray of lipid $^{\circ}$ solutions ${ }^{\circ}$ in $^{\circ}$ aqueous $^{\circ}$ ammonium $^{\circ}$ acetate $^{\circ}[24] .{ }^{\circ}$ In the present study, however, the aim was to generate significant abundances of phospholipid dimers where the primary interaction between the bonding partners was the sharing of a proton between negatively charged head-groups. This was achieved by conventional ESI of mixtures of phospholipids at concentrations of typically $80 \mu \mathrm{M}$ in a methanol/chloroform solvent mixture (with a solvent ratio of ca. 1:3). The relatively low polarity of this solvent mixture promotes interactions between the polar phospholipid headgroups similar to those in an inverse micelle. The ESI-MS spectrum of a solution containing equimolar dipalmitoyl PA and dipalmitoyl $\mathrm{PE}^{\circ}$ is ${ }^{\circ}$ shown $^{\circ}$ in ${ }^{\circ}$ Figure $^{\circ} 2 .^{\circ}$ The $^{\circ}$ major ${ }^{\circ}$ features ${ }^{\circ}$ of ${ }^{\circ}$ this spectrum are (1) the ions observed at $\mathrm{m} / \mathrm{z} 647.5$ and 690.6, which correspond to $[\mathrm{PA}(16: 0,16: 0)-\mathrm{H}]^{-}$and $[\mathrm{PE}(16: 0,16: 0)-\mathrm{H}]^{-}$, respectively, and (2) the ions observed at $m / z 1295.9,1338.9$, and 1382.0, which correspond to the proton bound dimers, $[\mathrm{PA}(16: 0,16: 0)-\mathrm{H}-$ PA(16:0,16:0) $]^{-}, \quad[\mathrm{PA}(16: 0,16: 0)-\mathrm{H}-\mathrm{PE}(16: 0,16: 0)]^{-}$, and [PE(16:0,16:0)-H-PE(16:0,16:0)] $]^{-}$, respectively. ESI conditions were adjusted in order to optimize the abundance of the $[\mathrm{PA}(16: 0,16: 0)-\mathrm{H}-\mathrm{PE}(16: 0,16: 0)]^{-}$dimer and typical conditions are provided in the methods section.

The $[\mathrm{PA}(16: 0,16: 0)-\mathrm{H}]^{-} /[\mathrm{PE}(16: 0,16: 0)-\mathrm{H}]^{-}$ratio in the $^{\circ}$ ESI-MS $^{\circ}$ spectrum $^{\circ}$ shown $^{\circ}$ in $^{\circ}$ Figure $^{\circ} 2^{\circ}$ is ${ }^{\circ}$ clearly greater than one, which is consistent with the preferential detection of PA observed in previous studies of phospholipid $^{\circ}$ mixtures $^{\circ}\left[11,{ }^{\circ} 12\right] .^{\circ}$ The $^{\circ}$ ion $^{\circ}$ abundance ratios for the full range of phospholipid pairs examined by $^{\circ}$ this ${ }^{\circ}$ method $^{\circ}$ are $^{\circ}$ listed $^{\circ}$ in $^{\circ}$ Table $^{\circ} 1 .^{\circ}$ These $^{\circ}$ data ${ }^{\circ}$ were obtained at lower cone and capillary voltages $(40 \mathrm{~V}$ and $3 \mathrm{kV}$, respectively) to minimize source fragmentation and provide an order of ionization efficiency of $\mathrm{PE}<\mathrm{PS}$ $<$ PA $<$ PG that is analogous to that previously 
Table 1. The ratio of phospholipid $[\mathrm{M}-\mathrm{H}]^{-}$anion abundances observed in the negative ion ESI-MS spectra of equimolar mixtures of two phospholipid species ( $80 \mu \mathrm{M}$ total phospholipid). These ratios were obtained using lower cone and capillary voltages to avoid fragmentation of phospholipid $[\mathrm{M}-\mathrm{H}]^{-}$anions $($ cone $=40 \mathrm{~V}$ and capillary $=3 \mathrm{kV})$.

\begin{tabular}{lcc}
\hline \multicolumn{2}{c}{ Phospholipid mixtures } & $\begin{array}{c}\text { Ion abundance ratio } \\
{\left[\mathrm{PL}_{1}-\mathrm{H}\right]^{-} /\left[\mathrm{PL}_{2}-\mathrm{H}\right]^{-}}\end{array}$ \\
\hline \hline $\mathrm{PA}(16: 0,16: 0)$ & $\mathrm{PE}(16: 0,16: 0)$ & $1.01 \times 10^{1}$ \\
$\mathrm{PA}(16: 0,16: 0)$ & $\mathrm{PG}(16: 0,16: 0)$ & $7.62 \times 10^{-1}$ \\
$\mathrm{PA}(16: 0,16: 0)$ & $\mathrm{PS}(16: 0,16: 0)$ & $1.91 \times 10^{0}$ \\
$\mathrm{PE}(16: 0,16: 0)$ & $\mathrm{PG}(16: 0,16: 0)$ & $2.92 \times 10^{-2}$ \\
$\mathrm{PG}(16: 0,16: 0)$ & $\mathrm{PS}(16: 0,16: 0)$ & $3.28 \times 10^{0}$ \\
$\mathrm{PS}(16: 0,16: 0)$ & $\mathrm{PE}(16: 0,16: 0)$ & $1.69 \times 10^{1}$ \\
\hline
\end{tabular}

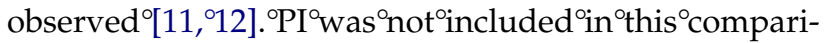
son as it was obtained as a mixture resulting in complications in the ESI-MS spectrum.

Once formed in sufficient abundance, dimer anions were mass-selected and subjected to collision induced dissociation. ${ }^{\circ}$ Figure $3 \mathrm{a}^{\circ}$ shows ${ }^{\circ}$ the ${ }^{\circ} \mathrm{ESI}-\mathrm{MS} / \mathrm{MS}^{\circ}$ spectrum of the proton bound dimer of dipalmitoyl PA and dipalmitoyl PE, denoted [PA(16:0,16:0)-H-PE(16:0, $16: 0)]^{-}$. The full scan $(\mathrm{m} / \mathrm{z} 150-1500)$ shows two major fragments at $m / z 647.2$ and 690.3 that correspond to the deprotonated PA and PE anions, respectively. At the collision energy and gas pressure used in this experiment, dissociation of the dimer was the only major fragmentation pathway observed. A minor fragment at $\mathrm{m} / \mathrm{z} 770.2$ was also observed, corresponding to a neutral loss of a diacyl glycerol. This fragment may arise from the intra-complex nucleophilic attack of a phosphate anion on the phosphorous of the PA, thus displacing the diacyl glycerol moiety and forming a diphosphate ester according to the mechanism shown in Scheme 1. The formation of diphosphates in the gas phase has been ${ }^{\circ}$ observed ${ }^{\circ}$ previously $^{\circ}[25]^{\circ}$ and $^{\circ}$ was $^{\circ}$ supported $^{\circ}$ in these experiments by the ESI-MS/MS spectra of analo-

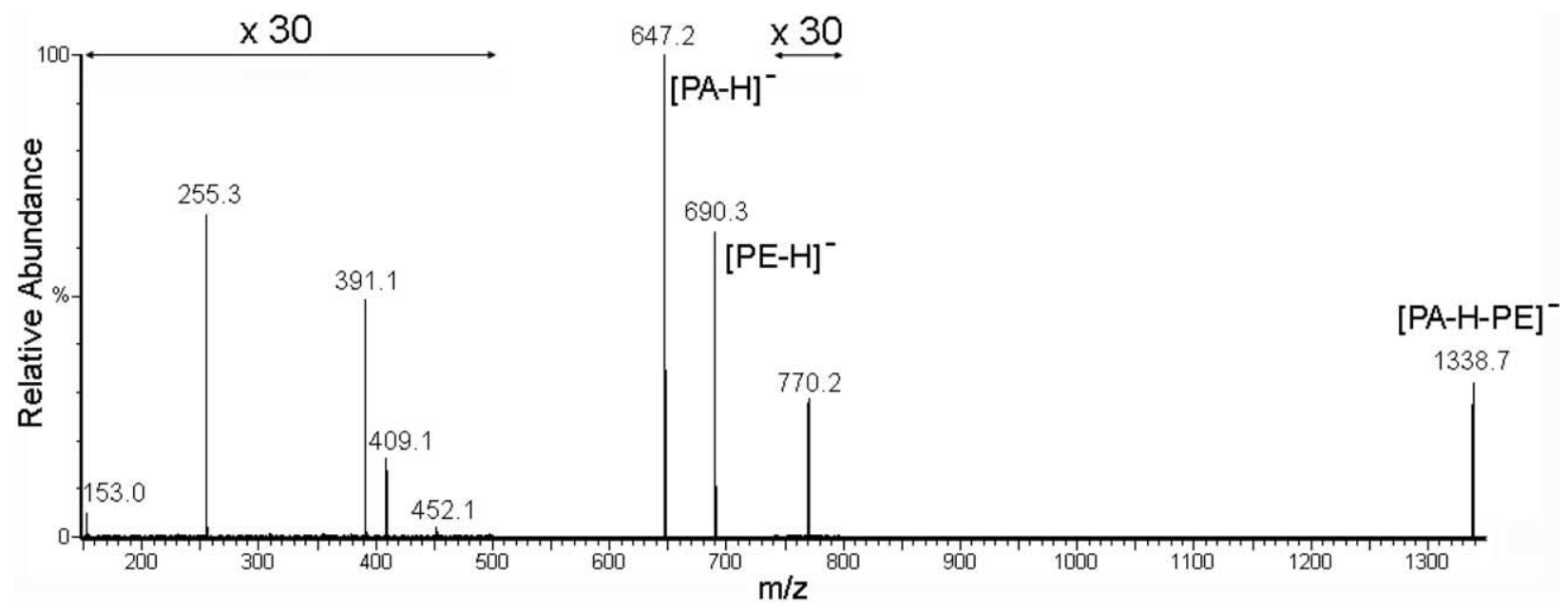

(a)

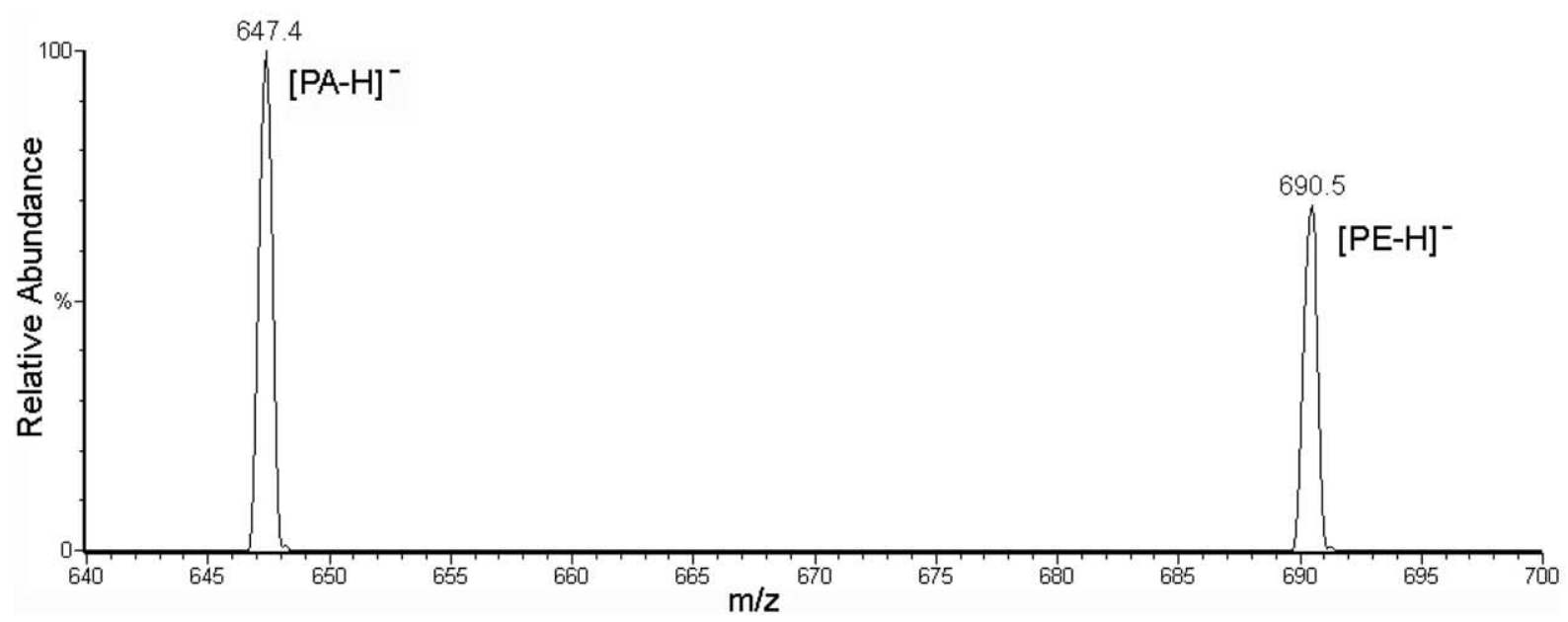

(b)

Figure 3. (a) ESI-MS/MS spectrum of the $[\mathrm{PA}(16: 0,16: 0)-\mathrm{H}-\mathrm{PE}(16: 0,16: 0)]^{-}$proton bound dimer $(\mathrm{m} / \mathrm{z}$ 1338.7). The mass ranges $\mathrm{m} / \mathrm{z} 150-500$ and $\mathrm{m} / \mathrm{z}$ 740-790 have both been expanded 30 times. (b) ESI-MS/MS spectrum of the [PA(16:0,16:0)-H-PE(16:0,16:0)] $]^{-}$proton bound dimer $(\mathrm{m} / z$ 1338.7) accumulated over a limited mass window $(\mathrm{m} / \mathrm{z} 640-700)$ an average of more than 300 scans. 


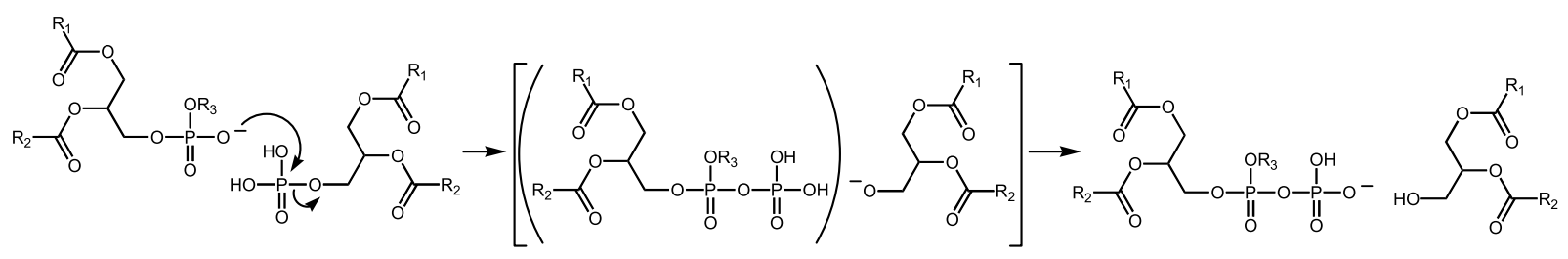

Scheme 1.

gous source formed ions, which showed characteristic $\mathrm{H}_{2} \mathrm{P}_{2} \mathrm{O}_{6}^{-}$and $\mathrm{PO}_{3}^{-}$fragments*. Loss of diacyl glycerol was also observed for other dimers containing PA (see Table $\left.{ }^{\circ} 2\right),{ }^{\circ}$ presumably ${ }^{\circ}$ because $^{\circ}$ the ${ }^{\circ}$ relatively ${ }^{\circ}$ low $^{\circ}$ steric hindrance of this headgroup facilitates the substitution reaction (cf. Scheme 1). In all cases however, such fragments are minor compared with simple dissociation of the dimer.

Secondary ${ }^{\circ}$ fragments $^{\circ}$ are $^{\circ}$ also $^{\circ}$ observed $^{\circ}$ in $^{\circ}$ Figure $^{\circ} 3$, arising from the deprotonated PA and PE anions. These include $^{\circ}$ palmitate $^{\circ}$ anions $^{\circ}(\mathrm{m} / \mathrm{z} 255.3)^{\circ}$ and $^{\circ}$ fragments arising from the neutral loss of palmitic acid from [PA $-\mathrm{H}]^{-}$at $m / z 391.1$ and ketene losses from [PA $\left.-\mathrm{H}\right]^{-}$ and $[\mathrm{PE}-\mathrm{H}]^{-}$at $m / z 409.1$ and 452.1 , respectively. These fragmentation pathways have previously been characterized for the tandem mass spectra of deprotonated ${ }^{\circ} \mathrm{PA}^{\circ}$ and ${ }^{\circ} \mathrm{PE}^{\circ}$ anions ${ }^{\circ}\left[16,{ }^{\circ} 17\right] .{ }^{\circ}$ These $^{\circ}$ secondary fragments constitute only $2 \%$ of the ion current in this spectrum, despite the fact that fragmentation of deprotonated phospholipids during collision induced dissociation ${ }^{\circ}$ is $^{\circ} \mathrm{known}^{\circ}$ to $^{\circ} \mathrm{be}^{\circ}$ facile $\left[15-18\right.$ ] $^{\circ}$ This ${ }^{\circ}$ suggests $^{\circ}$ that the abundances of phospholipid anions in the tandem

* The $m / z 770.2$ ion arising from the [PA(16:0,16:0)-H-PE(16:0,16:0)] ${ }^{-}$dimer system that was not formed in sufficient abundance in the ion source for ESI-MS/MS analysis. The ESI-MS/MS of source formed $\mathrm{m} / \mathrm{z} 735.2$ was obtained, however, for the [PA(16:0,16:0)-H-PA(16:0,18:1) $]^{-}$dimer system and gives: $m / z$ 753.3(6), 158.8(56), 78.7(169), where the values in parentheses are normalized peak abundances. The fragments observed at $\mathrm{m} / \mathrm{z} 158.8$ and 78.7 correspond to $\mathrm{H}_{2} \mathrm{P}_{2} \mathrm{O}_{6}^{-}$and $\mathrm{PO}_{3}^{-}$, respectively. mass spectra of proton bound dimers are not significantly affected by secondary fragmentation. The full scan tandem mass spectra of all phospholipid dimers are ${ }^{\circ}$ listed ${ }^{\circ}$ in $^{\circ} \mathrm{Table}^{\circ} 2$. $^{\circ} \mathrm{The}^{\circ}$ major ${ }^{\circ}$ fragments ${ }^{\circ}$ in $^{\circ}$ all ${ }^{\circ}$ spectra listed correspond to direct dissociation of the phospholipid dimers. Additional fragments in these spectra can, for the most part, be rationalized in terms of the minor primary and secondary processes discussed above. One further dissociation process is observed in the ESIMS/MS spectrum of the dimer, [PA(16:0,18:1)-HPS(16:0,16:0)] ${ }^{-}$, where 1-palmitoyl-2-oleoyl phosphatidic acid was used in place of 1,2-dipalmitoyl phosphatidic ${ }^{\circ}$ acid..$^{\circ}$ This $^{\circ}$ spectrum $^{\circ}\left(\text { Table }^{2}\right)^{\circ}$ shows ${ }^{\circ}$ the ${ }^{\circ}$ formation of predominantly the more acidic [PS(16:0,16:0)-H] anion at $m / z$ 735.0, however two ions at $m / z 674.6$ and 647.9 corresponding to [PA(16:0,18:1)-H] $]^{-}$and [PA(16: 0,16:0)-H] $]^{-}$are also observed. Fragmentation of [PS $\mathrm{H}^{-}$anions via loss of the head group as an $88 \mathrm{Da}$ neutral to yield the corresponding $[\mathrm{PA}-\mathrm{H}]^{-}$anion is well ${ }^{\circ} \mathrm{known}^{\circ}\left[7^{\circ}\right]^{\circ}$ and, ${ }^{\circ}$ as $^{\circ}$ such, $^{\circ}$ the ${ }^{\circ}$ additional ${ }^{\circ}$ ion ${ }^{\circ}$ in ${ }^{\circ}$ this spectrum could be attributed to secondary fragmentation of the PS anion. Alternatively, the [PA(16:0,16:0)$\mathrm{H}]^{-}$ion could arise directly from the dimer by a primary elimination mechanism such as that shown in Scheme 2. These two possibilities are difficult to distinguish experimentally, however, in either case such processes will result in a significant inflation of the $[\mathrm{PA}(16: 0,16: 0)-\mathrm{H}]^{-}$ion abundance in the ESI-MS/MS

Table 2. The negative ion ESI-MS/MS spectra of proton bound dimers $\left[\mathrm{PL}_{1}-\mathrm{H}-\mathrm{PL}_{2}\right]^{-}$. Fragment ions are listed as $m / z$ with normalized ion abundances given in parentheses.

\begin{tabular}{|c|c|c|}
\hline \multicolumn{2}{|c|}{ Phospholipid dimers $\left[\mathrm{PL}_{1}-\mathrm{H}-\mathrm{PL}_{2}\right]^{-}$} & Product ions $m / z{\text { (\%abundance })^{a}}^{a}$ \\
\hline $\operatorname{PA}(16: 0,16: 0)$ & $\operatorname{PE}(16: 0,16: 0)$ & $\begin{array}{l}1338.7(16.97), 770.2(0.53), 690.3(31.26), 647.2(49.08), 452.1(0.06), \\
409.1(0.30), 391.1(0.83), 255.3(0.87), 153.0(0.09)\end{array}$ \\
\hline $\mathrm{PA}(16: 0,16: 0)$ & $P G(16: 0,16: 0)$ & $\begin{array}{l}1369.7(6.27), 801.2(0.12), 721.3(92.19), 647.2(0.93), 483.0(0.06), 465.5(0.06) \text {, } \\
391.2(0.08), 255.2(0.24), 153.0(0.06)\end{array}$ \\
\hline $\mathrm{PA}(16: 0,16: 0)$ & $\mathrm{PS}(16: 0,16: 0)$ & $\begin{array}{l}\text { 1382.8(1.78), 734.2(96.11), 647.3(1.64), 408.9(0.04), 391.1(0.28), 255.2(0.11), } \\
153.0(0.04)\end{array}$ \\
\hline $\operatorname{PE}(16: 0,16: 0)$ & $P G(16: 0,16: 0)$ & $1412.8(0.71), 721.3(98.4), 690.1(0.38), 255.2(0.40), 153.1(0.06)$ \\
\hline$P G(16: 0,16: 0)$ & $\mathrm{PS}(16: 0,16: 0)$ & $\begin{array}{l}\text { 1456.8(2.45), 734.2(89.26), 721.3(6.47), 647.3(1.27), 409.0(0.10), 391.2(0.26), } \\
255.3(0.12), 153.1(0.08)\end{array}$ \\
\hline$P G(16: 0,16: 0)$ & $\mathrm{PI}(16: 0,18: 2)$ & $1555.8(2.30), 833.2(97.33), 721.3(0.37)$ \\
\hline PS(16:0,16:0) & $\mathrm{PI}(16: 0,18: 2)$ & 1568.8(5.41), 833.3(88.90), 734.3(5.69) \\
\hline $\mathrm{PA}(16: 0,18: 1)$ & $\operatorname{PS}(16: 0,16: 0)$ & $\begin{array}{l}1490.4(1.54), 735.0(94.74), 674.6(0.10), 647.9(2.45), 409.4(0.21), 391.4(0.48), \\
255.5(0.35), 153.1(0.13)\end{array}$ \\
\hline $\mathrm{PE}(16: 0,16: 0)$ & $\operatorname{PE}(17: 0,17: 0)$ & $1409.9(2.76), 718.3(53.84), 690.3(42.51), 452.0(0.18), 269.3(0.41), 255.3(0.30)$ \\
\hline $\operatorname{PA}(16: 0,16: 0)$ & $\mathrm{PA}(16: 0,18: 1)$ & $\begin{array}{l}\text { 1321.7(28.58), 753.2(3.08), 727.2(2.90), 673.3(33.88), 647.3(27.96), } \\
417.2(0.33), 409.1(0.51), 391.1(1.74), 281.2(0.34), 255.3(0.48), 153.0(0.19)\end{array}$ \\
\hline $\mathrm{PS}(16: 0,16: 0)$ & $\mathrm{PS}(18: 0,18: 0)$ & $1525.9(7.80), 790.3(52.50), 734.3(38.59), 703.4(0.55), 647.3(0.55)$ \\
\hline
\end{tabular}

alon abundance is normalized to the sum of all ion abundances i.e., $\mathrm{I}_{1}$ (normalized) $=\mathrm{I}_{1}(\%$ base peak $) / \Sigma_{\mathrm{i}} \mathrm{I}_{\mathrm{i}}(\%$ base peak) 

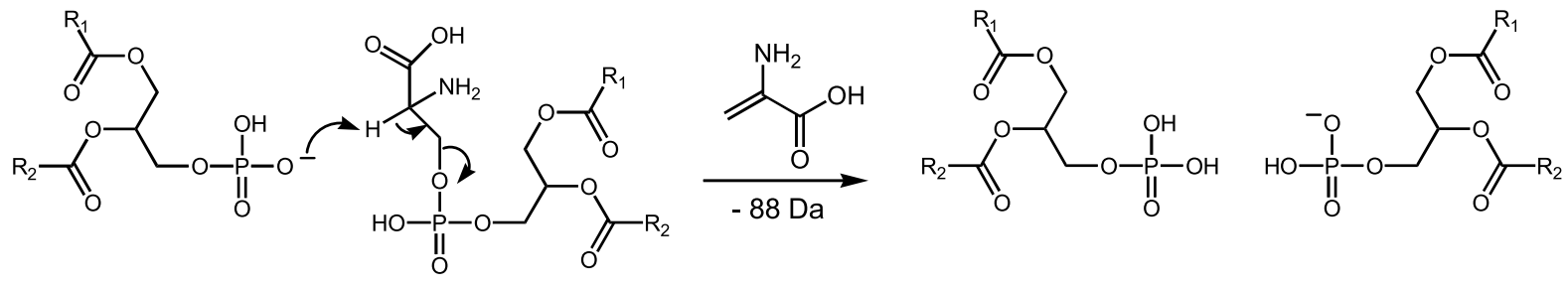

Scheme 2.

spectrum of the $[\mathrm{PA}(16: 0,16: 0)-\mathrm{H}-\mathrm{PS}(16: 0,16: 0)]^{-}$dimer. As a consequence, the ion abundance ratio listed for this dimer ${ }^{\circ}$ in $^{\circ}$ Table $^{\circ} 3^{\circ}$ has $^{\circ}$ been $^{\circ}$ corrected $^{\circ}$ by $^{\circ}$ assuming ${ }^{\circ}$ that the contribution of this pathway is identical for dissociation of the $[\mathrm{PA}(16: 0,16: 0)-\mathrm{H}-\mathrm{PS}(16: 0,16: 0)]^{-}$and [PA(16:0,18:1)-H-PS(16:0,16:0) $]^{-}$dimers.

The surprising simplicity of the ESI-MS/MS data obtained for the proton bound phospholipid dimers, in particular the absence of major complicating spectral features, suggests that these data are amenable to analysis by the kinetic method. In order to provide an improved statistical analysis of the relative ion abundances of the phospholipid anions, ESI-MS/MS spectra were obtained using a narrow mass window (e.g., $\mathrm{m} / \mathrm{z}$ 600-800) and were averaged over a greater number of scans (ca. 300). An example of such a zoom scan spectrum obtained for [PA(16:0,16:0)-H-PE(16:0,16:0)] is $^{\circ}$ shown $^{\circ}$ in $^{\circ}$ Figure $^{\circ} 3 \mathrm{~b}^{\circ}$ and ${ }^{\circ}$ the ${ }^{\circ}$ ratio $^{\circ}$ of ${ }^{\circ}$ integrated ${ }^{\circ}$ peak areas $^{\circ}$ are $^{\circ}$ presented ${ }^{\circ}$ in $^{\circ}$ Table $^{\circ} 3^{\circ}$ along $^{\circ}$ with ${ }^{\circ}$ those ${ }^{\circ}$ of ${ }^{\circ}$ the other proton bound dimers. Dissociation of the [PA (16:0,16:0)-H-PE(16:0,16:0)] ${ }^{-}$proton bound dimer gives an ion abundance ratio $[\mathrm{PA}(16: 0,16: 0)-\mathrm{H}]^{-} /[\mathrm{PE}(16: 0$, $16: 0)-\mathrm{H}^{-}$of 1.43 . The determination of a ratio greater than one indicates that $[\mathrm{PA}(16: 0,16: 0)-\mathrm{H}]^{-}$is formed preferentially upon competitive dissociation of the dimer and thus, PA is more acidic than PE in the gas phase. In the same way, the gas phase acidities of all the

Table 3. The ion abundance ratios $\left(\left[\mathrm{PL}_{1}-\mathrm{H}\right]^{-} /\left[\mathrm{PL}_{2}-\mathrm{H}\right]^{-}\right)$for collision induced dissociation of proton bound dimers $\left[\mathrm{PL}_{1}-\mathrm{H}-\right.$ $\left.\mathrm{PL}_{2}\right]^{-}$. The ion abundances used were measured from integrated peak areas in zoom scan ESI-MS/MS spectra averaged over 300 scans. Details of experimental conditions and post-acquisition processing are provided in the methods section.

\begin{tabular}{ccc}
\multicolumn{2}{c}{ Phospholipid pairs $\left[\mathrm{PL}_{1}-\mathrm{H}_{-} \mathrm{PL}_{2}\right]^{-}$} & \\
\hline $\mathrm{PL}_{1}$ & $\mathrm{PL}_{2}$ & $\begin{array}{l}\text { Ion abundance ratio } \\
{\left[\mathrm{PL}_{1}-\mathrm{H}\right]^{-} /\left[\mathrm{PL}_{2}-\mathrm{H}\right]^{-}}\end{array}$ \\
\hline \hline $\mathrm{PA}(16: 0,16: 0)$ & $\mathrm{PE}(16: 0,16: 0)$ & $1.43 \times 10^{0}$ \\
$\mathrm{PA}(16: 0,16: 0)$ & $\mathrm{PG}(16: 0,16: 0)$ & $1.08 \times 10^{-2}$ \\
$\mathrm{PA}(16: 0,16: 0)$ & $\mathrm{PS}(16: 0,16: 0)^{\mathrm{a}}$ & $6.62 \times 10^{-4}$ \\
$\mathrm{PE}(16: 0,16: 0)$ & $\mathrm{PG}(16: 0,16: 0)$ & $5.75 \times 10^{-3}$ \\
$\mathrm{PG}(16: 0,16: 0)$ & $\mathrm{PS}(16: 0,16: 0)$ & $6.74 \times 10^{-2}$ \\
$\mathrm{PG}(16: 0,16: 0)$ & $\mathrm{PI}(16: 0,18: 2)$ & $4.50 \times 10^{-3}$ \\
$\mathrm{PS}(16: 0,16: 0)$ & $\mathrm{PI}(16: 0,18: 2)$ & $1.93 \times 10^{-2}$ \\
$\mathrm{PE}(16: 0,16: 0)$ & $\mathrm{PE}(17: 0,17: 0)$ & $8.41 \times 10^{-1}$ \\
$\mathrm{PA}(16: 0,16: 0)$ & $\mathrm{PA}(16: 0,18: 1)$ & $8.37 \times 10^{-1}$ \\
$\mathrm{PS}(16: 0,16: 0)$ & $\mathrm{PS}(18: 0,18: 0)$ & $7.24 \times 10^{-1}$ \\
\hline
\end{tabular}

aThis ratio has been corrected to account for formation of [PA-H] anions from fragmentation of [PS-H] ${ }^{-}$determined from the ESI-MS/MS spectrum of [PA(16:0,18:1)-H-PS(16:0,16:0)] . phospholipid headgroups can be ranked such that in order of increasing acidity $\mathrm{PE}<\mathrm{PA}<\mathrm{PG}<\mathrm{PS}<\mathrm{PI}$. Several redundant measurements were also obtained to check the internal consistency of these data. For example, the ratios $[\mathrm{PS}-\mathrm{H}]^{-} /[\mathrm{PI}-\mathrm{H}]^{-}$and $[\mathrm{PG}-\mathrm{H}]^{-} /[\mathrm{PS}$ $-\mathrm{H}^{-}$are both less than unity indicating an order of acidities of PG $<$ PS $<$ PI, which is consistent with the $[\mathrm{PG}-\mathrm{H}]^{-} /[\mathrm{PI}-\mathrm{H}]^{-}$ratio of $4.5 \times 10^{-3}$ that independently confirms the ranking of PI as more acidic than $\mathrm{PG}^{\circ}$ (Table ${ }^{\circ}$ ).

Several proton bound dimers were also prepared between phospholipids with the same headgroups but with different fatty acids substituted on the glycerol backbone. The ions observed in the tandem mass $^{\circ}$ spectra $^{\circ}$ of $^{\circ}$ these $^{\circ}$ dimers $^{\circ}$ are $^{\circ}$ listed $^{\circ}$ in $^{\circ}$ Table $^{\circ} 2$ while the abundance ratio of the phospholipid fragment $^{\circ}$ ions $^{\circ}$ is $^{\circ}$ given $^{\circ}$ in $^{\circ}$ Table $^{\circ} 3 .^{\circ}$ These $^{\circ}$ data $^{\circ}$ show $^{\circ}$ a measurable effect on the dimer fragmentation kinetics brought about by relatively small alterations to the fatty acid substituents. For example, dissociation of the [PA(16:0,16:0)-H-PA(16:0,18:1) $]^{-}$dimer leads to preferential formation of the $[\mathrm{PA}(16: 0,18: 1)-\mathrm{H}]^{-}$anion, and similarly, dissociation of the [PS(16:0,16:0)H-PS(18:0,18:0)] $]^{-}$results in a greater abundance of [PS(18:0,18:0)-H] $]^{-}$. The measured ion abundance ratios are 0.841 and 0.724 , respectively, suggesting that the effect of the fatty acids on the competitive dissociation of phospholipid dimers is small compared with the gross differences observed between different headgroups ${ }^{\circ}\left(\right.$ Table $\left.^{\circ} 3\right) .{ }^{\circ}$ It $^{\circ}$ seems $^{\circ}$ unlikely ${ }^{\circ}$ that ${ }^{\circ}$ substitution of different fatty acids substantially alters the enthalpy of deprotonation for a phospholipid but rather results in a difference in entropy between the transition states for the two dissociation pathways (Scheme 3). In other words, the different ion abundances observed are more likely the result of differences in entropy rather than enthalpy. The comparison of fatty acid substituents suggests that the use of PI(16:0,18:2) instead of PI(16:0,16:0), because of the

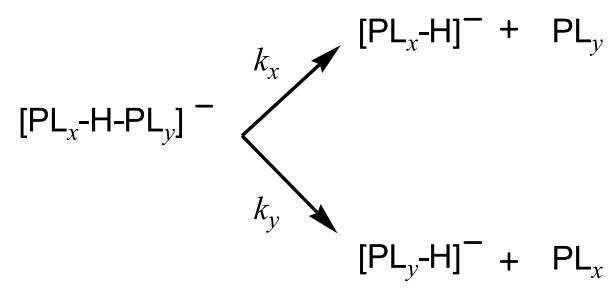

Scheme 3. 
unavailability of the latter, will affect the ion abundance ratios by at most $20-30 \%$. This discrepancy in ion abundance ratios does not alter the predicted order of gas phase acidities, nor does it significantly impact on the kinetic method calculations discussed below.

\section{The Kinetic Method}

Since it was first proposed by Cooks and Kruger in $1977^{\circ}[26]^{\circ}$ the ${ }^{\circ}$ applicability ${ }^{\circ}$ of $^{\circ}$ the ${ }^{\circ}$ kinetic $^{\circ}$ method $^{\circ}$ to thermochemical analysis has been extensively discussed $^{\circ}[27-35] .{ }^{\circ}{ }^{\circ}$ The ${ }^{\circ}$ kinetic $^{\circ}$ method $^{\circ}{ }^{\circ}$ can $^{\circ} b^{\circ}$ applied ${ }^{\circ}$ to the determination of gas phase acidities by examination of competitive dissociation of proton bound dimer anions. This is achieved by equating the ratio of the rate constants $\left(k_{x} / k_{y}\right)$ for the dissociation channels of the dimer, such as the phospholipid dimer shown in Scheme 3, with the ratio of the observed ion abundances $\left(I_{x} / I_{y}\right)$ in the tandem mass spectrum. From transition state theory, the natural $\log$ of this ratio is then related the difference in enthalpy, $\Delta H_{\text {acid }}\left(P L_{x}\right)-\Delta H_{\text {acid }}\left(P L_{y}\right)$, and entropy, $\Delta \Delta S$, between the competing dissociation channels, according to eq 1 , where $R$ is the gas constant and $T_{\text {eff }}$ is the effective temperature.

$$
\begin{aligned}
\ln \left(\frac{k_{x}}{k_{y}}\right) & \cong \ln \left(\frac{I_{x}}{I_{y}}\right) \\
& =-\frac{\left[\Delta H_{\text {acid }}\left(P L_{x}\right)-\Delta H_{\text {acid }}\left(P L_{y}\right)\right]}{R T_{\text {eff }}}+\frac{[\Delta \Delta S]}{R} \\
\ln \left(\frac{I_{x}}{I_{y}}\right) & \cong-\frac{\left[\Delta H_{\text {acid }}\left(P L_{x}\right)-\Delta H_{\text {acid }}\left(P L_{y}\right)\right]}{R T_{\text {eff }}}
\end{aligned}
$$

Implicit in this relationship is the assumption that the reverse activation barriers for the two dissociative channels are negligible (assumption 1), that is, there are no additional decomposition channels or isomeric forms of the activated cluster ion. In the standard kinetic method a second simplifying assumption is also made, namely that there is zero entropy difference between the competing dissociation channels, that is, $\Delta \Delta S=0$ (assumption 2). This assumption allows for the simplified expression in eq 2 and can be cautiously applied when the components of the dimer are chemically similar*. Application of the standard kinetic method typically involves the dissociation of a range of dimers comprising the target compound and a series of reference acids chemically similar to the target. Plotting $\ln \left(I_{x} / I_{y}\right)$ against the acidity of each reference acids-the so-

\footnotetext{
* The validity of this assumption can be examined in some instances by application of the extended kinetic method where the cluster ion is dissociated at a range of excitation energies. For further discussion on this topic the reader is referred to recent companion articles by Ervin and Armentrout (J. Mass Spectrom. 2004, 39, 1004-1015) and Drahos, Peltz and Vekey (J. Mass Spectrom. 2004, 39, 1016-1024).
}

called kinetic method plot-yields the deprotonation enthalpy of the target compound as the x-intercept, while $T_{\text {eff }}$ can be derived from the slope. The meaning of effective temperature has been discussed extensively $\left[32,{ }^{\circ} 34\right]^{\circ}$ but $^{\circ}$ it $^{\circ}$ is $^{\circ}$ now $^{\circ}$ broadly $^{\circ}$ accepted $^{\circ}$ that ${ }^{\circ} T_{\text {eff }}$ is a kinetic correlation parameter rather than a thermodynamic ${ }^{\circ}$ temperature ${ }^{\circ}[29] .{ }^{\circ}$ Independent ${ }^{\circ}$ simulations $^{\circ}$ by Ervin $^{\circ}[32]^{\circ}$ and ${ }^{\circ}$ Drahos $^{\circ}$ and $^{\circ}$ Vekey $^{\circ}[30]^{\circ}$ have $^{\circ}$ shown $^{\circ}$ a complicated dependence of $T_{\text {eff }}$ on both the nature of the dimer ion as well as instrumental parameters. The most critical molecular variables affecting $T_{\text {eff }}$ were found to be the association energy and number of degrees of freedom of the cluster ion, while instrumental parameters control the internal energy of the cluster ion and the measurable dissociation timescale.

In the present study, suitable reference acids, which are sufficiently acidic and structurally similar to the target phospholipids, are not available. In the absence of such standards, only a relative order of acidity could be determined by comparing the competitive dissociation ${ }^{\circ} f^{\circ}$ the ${ }^{\circ}$ phospholipid ${ }^{\circ}$ dimers $^{\circ}\left(\right.$ Table $^{\circ}$ 3). .This $^{\circ}$ simplistic application of the kinetic method yields the acidity trend, $\mathrm{PE}<\mathrm{PA}<\mathrm{PG}<\mathrm{PS}<\mathrm{PI}$, as previously discussed. To approximate the magnitude of the differences in deprotonation enthalpy an effective temperature of $600 \pm 300 \mathrm{~K}$ was estimated. This estimate was based on (1) the significant association energies of anion clusters $^{\circ}$ such $^{\circ}$ as $^{\circ}$ those ${ }^{\circ}$ examined $^{\circ}$ in $^{\circ}$ this $^{\circ}$ study, $^{\circ}(2)^{\circ}$ the large size of the phospholipid dimer ions all of which possess more than 600 degrees of freedom, and (3) the intermediate timescale of dissociation sampled by a triple ${ }^{\circ}$ quadrupole $\mathrm{e}^{\circ}$ mass $^{\circ}$ spectrometer $^{\circ}\left(\mathrm{ca}^{\circ} 10^{-4^{\circ}} \mathrm{s}\right)^{\circ}\left[30^{\circ}\right.$ 32]..$^{\circ} \mathrm{It}^{\circ}$ must $^{\circ}$ be $^{\circ}$ stressed $^{\circ}$ that $^{\circ}$ this $^{\circ}$ value $^{\circ}$ is ${ }^{\circ}$ only ${ }^{\circ}$ an estimate and furthermore the use of the same effective temperature for all phospholipid dimer combinations represents a significant assumption in itself (assumption 3 ). This assumption seems reasonable in this case however, as all experiments were carried out at the same laboratory frame collision energy $(30 \mathrm{eV})$ and the variation in both cluster ion $\mathrm{m} / \mathrm{z}$ and the number of degrees of freedom are small with respect to the size of the ions. For example, the relative change in $\mathrm{m} / \mathrm{z}$ and number of degrees of freedom from the smallest, [PA(16:0,16:0)-H$\mathrm{PE}(16: 0,16: 0)]^{-}$to the largest dimer, [PS(16:0,16:0)-H$\operatorname{PI}(16: 0,18: 2)]^{-}$, Is $^{\circ}$ only $17^{\circ}$ and $15 \%$, respectively $\left.{ }^{9} 30^{\circ}-32\right]$. As a result of this assumption, however, in addition to the inherent uncertainty in the initial estimation, a 50\% uncertainty ${ }^{\circ}$ has $^{\circ}$ been ${ }^{\circ}$ included $^{\circ}$ in ${ }^{\circ}$ the ${ }^{\circ}$ effective $e^{\circ}$ temperature ${ }^{\circ} \mathrm{as}^{\circ}$ recommended $^{\circ}$ by $^{\circ}$ Armentrout $^{\circ}[35]^{\circ} .^{\circ}$ Using ${ }^{\circ}$ an estimate $T_{\text {eff }}=600 \pm 300 \mathrm{~K}$ in eq 2 , along with the ion abundance ${ }^{\circ}$ data ${ }^{\circ}$ listed ${ }^{\circ}$ in ${ }^{\circ}$ Table 3 , ${ }^{\circ}{ }^{\circ}{ }^{\circ}$ acidity ${ }^{\circ}$ ladder ${ }^{\circ}$ was generated $^{\circ}\left(\right.$ Figure $\left.^{\circ}\right)$.

Although several key assumptions have been made to ${ }^{\circ}$ produce $^{\circ}$ the ${ }^{\circ}$ data $^{\circ}$ shown $^{\circ}$ in $^{\circ}$ Figure $^{\circ} 4,{ }^{\circ}$ the ${ }^{\circ}$ internal consistency between the relative acidities obtained generally supports the approach utilized in this study. For example, the sum of (1) the difference in deprotonation enthalpies between PE and PA, $\Delta \Delta H_{\text {acid }}(\mathrm{PE}-\mathrm{PA})=2 \mathrm{~kJ}$ $\mathrm{mol}^{-1}$, and (2) the analogous spacing between PA and 


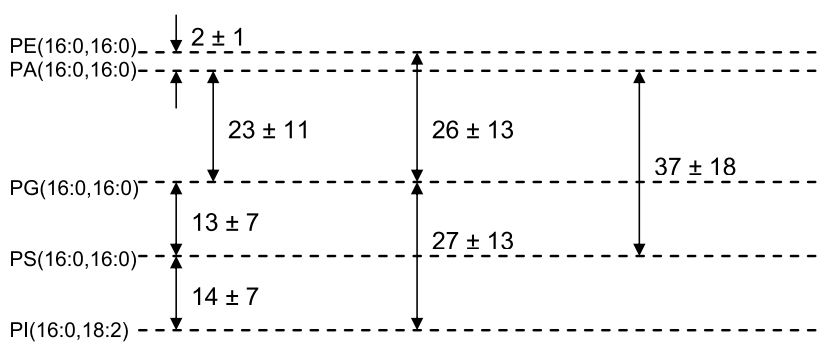

Figure 4. The ladder diagram showing the relative gas phase acidities of the phospholipid classes determined from the kinetic method. The significant uncertainties arise from the estimation of the effective temperature, $T_{\text {eff }}=600 \pm 300 \mathrm{~K}$.

PG, $\Delta \Delta H_{\text {acid }}(\mathrm{PA}-\mathrm{PG})=23 \mathrm{~kJ} \mathrm{~mol}^{-1}$, is extremely close to the relative enthalpy change for the overlapping measurement, $\Delta \Delta H_{\text {acid }}(\mathrm{PE}-\mathrm{PG})=26 \mathrm{~kJ} \mathrm{~mol}^{-1}$. Similar agreement is observed for the redundant measurements, $\Delta \Delta H_{\text {acid }}\left(\right.$ PA-PS) $=37 \mathrm{~kJ} \mathrm{~mol}^{-1}$ and $\Delta \Delta H_{\text {acid }}(\mathrm{PG}-$ $\mathrm{PI})=27 \mathrm{~kJ} \mathrm{~mol}^{-1}$. The internal consistency of these data lend support to the assigned energy spacings and the underlying assumptions of uniform entropy (assumption 2) and uniform effective temperature (assumption 3), implicit $^{\circ}$ in $^{\circ}$ the $^{\circ}$ generation $^{\circ}$ of $^{\circ}$ Figure $^{\circ} 4 . .^{\circ}$ In $^{\circ}$ an $^{\circ}$ effort $^{\circ}$ to further support these findings, as well as to provide a structural rationale for the experimental observations, electronic structure calculations were carried out.

\section{Electronic Structure Calculations}

Given the large size ( $>40$ heavy atoms) and the number of degrees of conformational freedom in phospholipid molecules a model study was devised where the diacylglycerol moiety was represented by a methyl group. This approach allowed for the relatively rapid optimization of numerous local minima for a particular phospholipid and its deprotonated conjugate base at the Becke3LYP/6-31+ $\mathrm{G}(\mathrm{d})$ level of theory. The structures of neutral and anionic global minima located in this study are represented in Figure ${ }^{\circ}{ }^{\circ}$ and ${ }^{\circ}$ full ${ }^{\circ}$ structural ${ }^{\circ}$ details in the ${ }^{\circ}$ form ${ }^{\circ}$ of ${ }^{\circ}$ artesian coordinates are provided in the Appendices. Single point energy calculations using the expanded Becke3LYP/6-311 $++G(d, p)$ were conducted for these structures and the results $^{\circ}$ are $^{\circ}$ presented $^{\circ}$ in $^{\circ}$ Table $^{\circ} 4 .^{\circ}$ The $^{\circ}$ analogous ${ }^{\circ}$ calculations were also conducted for phosphoric acid and these data were used to compute the reaction enthalpy of the isodesmic reaction outlined in Scheme 4. The enthalpy of this reaction can be considered as the difference in the gas phase enthalpies of deprotonation between phosphoric acid and the target phospholipid, i.e., $\Delta H_{\text {reaction }}$ (Scheme 4) $=\Delta H_{\text {acid }}\left[\mathrm{H}_{3} \mathrm{PO}_{4}\right]-\Delta H_{\text {acid }}[\mathrm{PL}]$. Using the reported deprotonation enthalpy of phosphoric acid $\left(\Delta_{\text {acid }} \mathrm{H}_{298}\left[\mathrm{H}_{3} \mathrm{PO}_{4}\right]\right.$ $\left.={ }^{\circ} 1383^{\circ} \pm 21 \mathrm{~kJ}^{\circ} \mathrm{mol}^{-1}\right)^{\circ}[19]^{\circ}$ the ${ }^{\circ}$ deprotonation ${ }^{\circ}$ enthalpy of the phospholipid classes were determined and the results are $^{\circ}$ presented ${ }^{\circ}{ }^{\circ}{ }^{\circ}$ Table 5 .

PA is the simplest phospholipid class, with strong structural similarities to phosphoric acid. The optimized structure of $[\mathrm{PA}-\mathrm{H}]^{-}$obtained in this study is consistent with that reported previously by Vigroux and ${ }^{\circ}$ coworkers ${ }^{\circ}[36] .{ }^{\circ}$ The $^{\circ}$ structure ${ }^{\circ}$ of ${ }^{\circ}\left[\mathrm{PA}-{ }^{\circ} \mathrm{H}\right]^{-}{ }^{\circ}$ (Figure $5 \mathrm{~d})^{\circ}$ was $^{\circ}$ found ${ }^{\circ}$ to $^{\circ}$ have $^{\circ}$ an $^{\circ}$ optimal ${ }^{\circ} \mathrm{OH}$. . . OP distance of $2.47 \AA$ that is considerably shorter than both (1) comparable interactions in the corresponding neutral $\left(\mathrm{OH} \ldots \text {. . OP }{ }^{\circ} \text { distance }{ }^{\circ} \text { of }^{\circ} 2.65^{\circ} \AA{ }^{\circ}, \text { Figure }^{\circ} 5 \mathrm{c}\right)^{\circ}$ and ${ }^{\circ}(2)^{\circ}$ the sum of the van der Waals radii for hydrogen and $\operatorname{oxygen}^{\circ}\left(2.72^{\circ} \AA\right)^{\circ}[37]^{\top}$ This $^{\circ}$ structural $^{\circ}$ feature ${ }^{\circ}$ of the ${ }^{\circ}$ anion suggests that hydrogen bonding plays a role in solvating the negative charge on phosphate. Deprotonation of $\mathrm{PA}$ is calculated to require $1388 \mathrm{~kJ} \mathrm{~mol}^{-1}$, and thus, PA is predicted to be slightly less acidic than phosphoric acid. The small difference in acidity (ca. $5 \mathrm{~kJ} \mathrm{~mol}^{-1}$ ) can be rationalized by the presence of only a single hydrogen bonding interaction in $[\mathrm{PA}-\mathrm{H}]^{-}$compared with two comparable interactions in $\mathrm{H}_{2} \mathrm{PO}_{4}^{-}$.

The $^{\circ}$ optimized $^{\circ}$ structure $^{\circ}$ of $^{\circ} \mathrm{PE}^{\circ}$ is ${ }^{\circ}$ shown $^{\circ}$ in ${ }^{\circ}$ Figure $^{\circ} 5 \mathrm{e}$ and ilustrates the global minimum to be a cyclized conformer with hydrogen bonding interaction between the acidic phosphate bound proton and the nonbonding electron pair on the nitrogen. The relatively short $\mathrm{OH} \ldots \mathrm{N}$ distance $(<1.8 \AA)$ and the difference in energy between this structure and open chain conformers (ca. $20 \mathrm{~kJ} \mathrm{~mol}^{-1}$ ) suggests that this proton is tightly bound in the neutral. Attempts to locate a zwitterionic structure for PE with a formal phosphate anions and an ammonium cation resulted in proton transfer and optimization to a global minimum with no formal charge. The absence of a gas phase zwitterionic local minimum has been reported previously by Landin et al. who also located a cyclic global minimum ${ }^{\circ}$ similar $^{\circ}$ in $^{\circ}$ structure $^{\circ}$ to ${ }^{\circ}$ that ${ }^{\circ}$ reported ${ }^{\circ}$ here ${ }^{\circ}$ [38]. The strong hydrogen bonding interaction observed for neutral ${ }^{\circ} \mathrm{PE}^{\circ}\left(\text { Figure }^{\circ} 5 \mathrm{e}\right)^{\circ}$ is $^{\circ}$ absent $^{\circ}{ }^{\circ}{ }^{\circ}\left[\mathrm{PE}^{\circ}-{ }^{\circ} \mathrm{H}\right]^{-}{ }^{\circ}$ (Figure $\left.{ }^{\circ} 5 f\right)$, which may explain why the deprotonation enthalpy of $\mathrm{PE}$ is predicted to be about $2 \mathrm{~kJ} \mathrm{~mol}^{-1}$ greater than that of PA (Table ${ }^{\circ}$ )..$^{\circ}$ The ${ }^{\circ}$ gas $^{\circ}$ phase ${ }^{\circ}$ acidity $^{\circ}$ of ${ }^{\circ} E^{\circ}$ with ${ }^{\circ}$ respect ${ }^{\circ}$ to ${ }^{\circ} \mathrm{PA}$ is in excellent quantitative agreement with experiment.

The optimized structures for neutral and deprotonated PG demonstrate the importance of hydrogen bonding interactions between the glycerol headgroup and the phosphate moiety. The significant contraction of some of the hydrogen bonds in the structure of [PG $-\mathrm{H}]^{-}$, compared with PG (e.g., PO ... H-O distances of $1.95 \AA$ compared with $2.27 \AA$ ), suggests that these interactions play a greater role in stabilization of the anion ${ }^{\circ}$ than ${ }^{\circ} n^{\circ}$ the $^{\circ}$ corresponding $^{\circ}$ neutral ${ }^{\circ}$ (Figure ${ }^{\circ} 5 g^{\circ}$ and h). Preferential stabilization of the deprotonated species is responsible for the substantial increase in gas phase acidity predicted for PG $\left(\Delta H_{\mathrm{acid}}[\mathrm{PG}]=1339 \mathrm{~kJ} \mathrm{~mol}^{-1}\right)$ compared to PA and PE. This trend is analogous to the experimental observations described above, although the calculated difference in deprotonation enthalpy $\Delta \Delta H_{\text {acid }}\left[\mathrm{PA}^{\circ}-\mathrm{PG}^{\circ}=49 \mathrm{~kJ}^{\circ} \mathrm{mol}^{-1^{\circ}}\right.$ (Table 5 ) is larger than the ${ }^{\circ}$ experimental ${ }^{\circ}$ value $^{\circ}$ of ${ }^{\circ} 23^{\circ} \mathrm{kJ}^{\circ} \mathrm{mol}^{-1^{\circ}}$ (Figure ${ }^{\circ} 4$ ).

The ${ }^{\circ}$ lowest ${ }^{\circ}$ energy $^{\circ}$ structure $^{\circ}$ of ${ }^{\circ} S^{\circ}\left(\text { Figure }^{\circ} 5 i\right)^{\circ}$ adopts a cyclic conformation to maximize the hydrogen bonding interaction between the nonbonding electron pair on nitrogen and the acidic phosphate proton: a structural motif similar to that observed previously for PE. The carboxylic acid moiety in the PS structure is also 
(a)

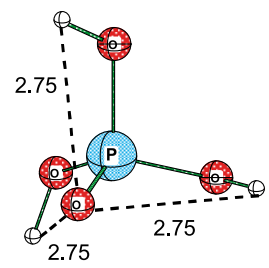

(c)
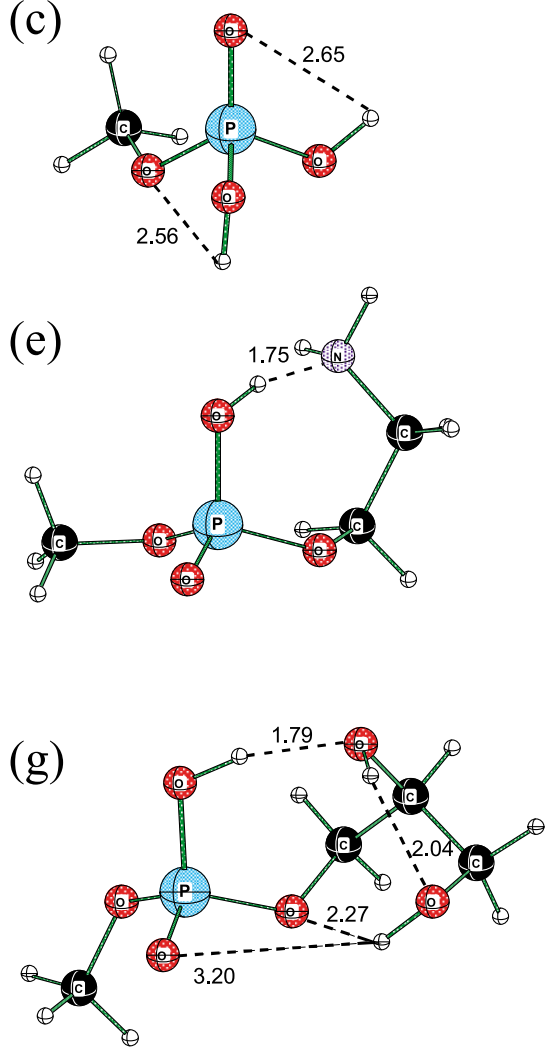

(i)
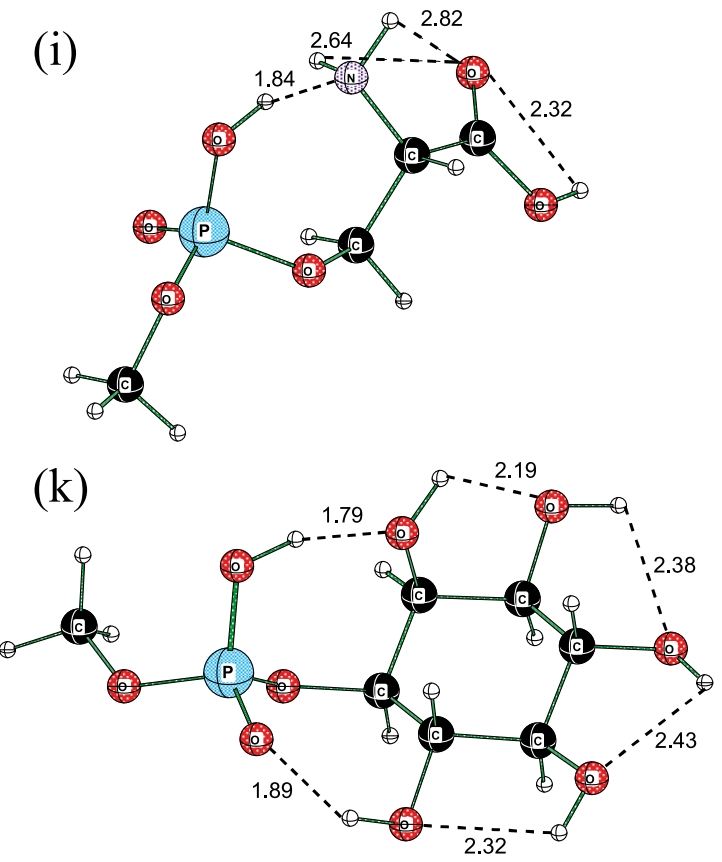

(b)

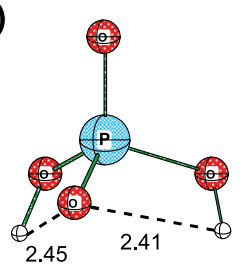

(d)
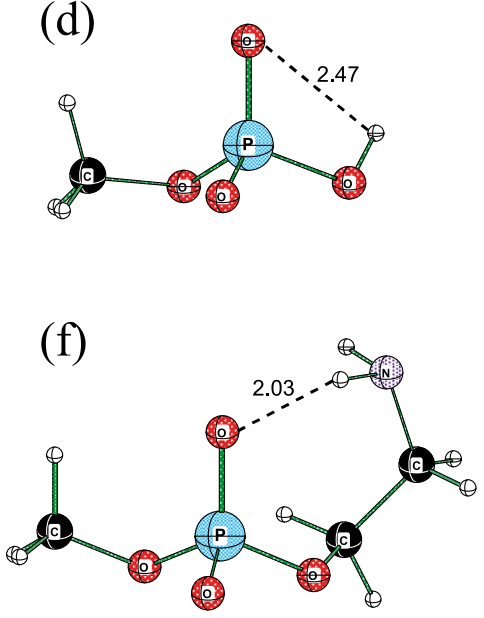
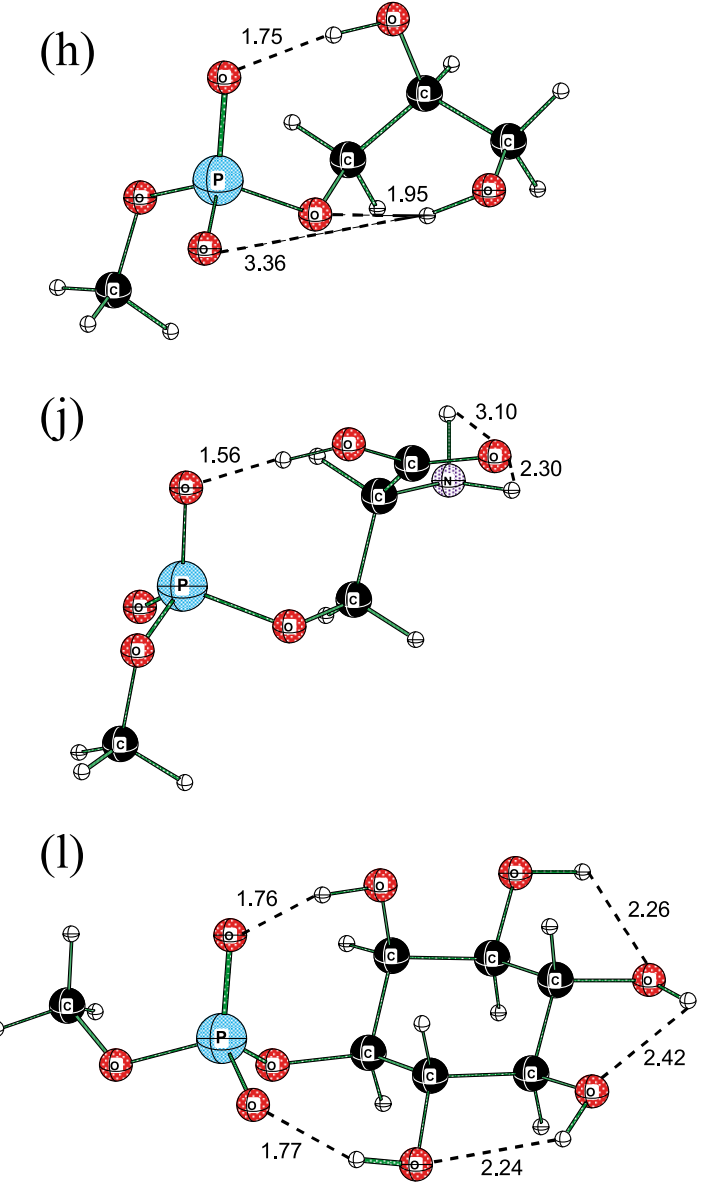

Figure 5. The molecular structures for the global minima for phosphoric acid, neutral phospholipids and their conjugate anionic bases calculated at the B3LYP/6-31 $+\mathrm{G}(\mathrm{d})$ level of theory: $(\mathbf{a}) \mathrm{H}_{3} \mathrm{PO}_{4}$, (b) $\mathrm{H}_{2} \mathrm{PO}_{4}^{-}$, (c) PA, (d) $[\mathrm{PA}-\mathrm{H}]^{-}$, (e) $\mathrm{PE},(\mathbf{f})[\mathrm{PE}-\mathrm{H}]^{-}$, (g) PG, (h) $[\mathrm{PG}-\mathrm{H}]^{-}$, (i) PS, (j) $[\mathrm{PS}-\mathrm{H}]^{-}$, (k) $\mathrm{PI}$, and (1) $[\mathrm{PI}-\mathrm{H}]^{-}$. 
Table 4. The electronic energy, zero-point and thermal corrections ( $298.15 \mathrm{~K})$ for the optimized structures shown in Figure 5 . All values are listed in units of Hartrees.

\begin{tabular}{|c|c|c|c|c|}
\hline Molecule & $\begin{array}{l}\text { Electronic energy } \\
\text { B3LYP/6-31+G(d) }\end{array}$ & $\begin{array}{l}\text { Zero-point } \\
\text { correction }\end{array}$ & $\begin{array}{l}\text { Thermal } \\
\text { correction }\end{array}$ & $\begin{array}{c}\text { Electronic Energy } \\
\text { B3LYP/6-311++G(d,p) }\end{array}$ \\
\hline $\mathrm{H}_{3} \mathrm{PO}_{4}$ & -644.15495 & 0.04788 & 0.05511 & -644.28154 \\
\hline $\mathrm{H}_{2} \mathrm{PO}_{4}^{-}$ & -643.63114 & 0.03636 & 0.04307 & -643.75183 \\
\hline PE & -817.43874 & 0.15366 & 0.16528 & -817.60150 \\
\hline$[\mathrm{PE}-\mathrm{H}]^{-}$ & -816.90770 & 0.14029 & 0.15198 & -817.06596 \\
\hline PA & -683.45966 & 0.07699 & 0.08562 & -683.59038 \\
\hline$[\mathrm{PA}-\mathrm{H}]^{-}$ & -682.93299 & 0.06494 & 0.07307 & -683.05791 \\
\hline PG & -951.83510 & 0.17451 & 0.18801 & -952.04062 \\
\hline$[\mathrm{PG}-\mathrm{H}]^{-}$ & -951.32369 & 0.16124 & 0.17444 & -951.52445 \\
\hline PS & -1006.01703 & 0.16832 & 0.18279 & -1006.23436 \\
\hline$[\mathrm{PS}-\mathrm{H}]^{-}$ & -1005.51111 & 0.15529 & 0.16921 & -1005.72404 \\
\hline PS (Zwitterion) & -1006.00601 & 0.16909 & 0.18263 & -1006.22079 \\
\hline [PS-H] $^{-}$(Zwitterion) & -1005.50828 & 0.15585 & 0.16950 & -1005.71858 \\
\hline $\mathrm{PI}$ & -1294.24470 & 0.25237 & 0.27111 & -1294.55447 \\
\hline$[\mathrm{PI}-\mathrm{H}]^{-}$ & -1293.73893 & 0.23979 & 0.25802 & -1294.04312 \\
\hline
\end{tabular}

aligned to maximize stabilizing interactions with the amino hydrogens. Zwitterionic isomers of PS are also local minima on the potential energy surface but these structures were found to be higher in energy than the global ${ }^{\circ}$ minima ${ }^{\circ}$ by $^{\circ} 36^{\circ} \mathrm{kJ}^{\circ} \mathrm{mol}^{-1^{\circ}}\left(\right.$ Table $\left.^{\circ} 4\right) .{ }^{\circ} \mathrm{In}^{\circ}$ the ${ }^{\circ}$ other phospholipid ${ }^{\circ}$ systems ${ }^{\circ}$ shown ${ }^{\circ}{ }^{\circ}$ Figure ${ }^{\circ}$, the ${ }^{\circ}$ optimized geometries of the model acid and conjugate base where found to be similar. In all cases, the change in conformation brought about by deprotonation amounts to minor reorientation of hydroxyl or amine moieties to stabilize the charged phosphate. In contrast, the lowest energy structure of $[\mathrm{PS}-\mathrm{H}]^{-}$differs substantially from the lowest energy structure of PS. The optimized structure of the anion adopts an alternative cyclic conformation to maximize the interaction between the carboxylic acid proton and one of the oxygen atoms of the charge bearing ${ }^{\circ}$ phosphate ${ }^{\circ}$ (Figure $\left.{ }^{\circ} 5 j\right) .^{\circ}$ This $^{\circ}$ noncovalent ${ }^{\circ}$ interaction is optimized at a distance of just $1.56 \AA$ that represents the most intimate hydrogen bond observed in $^{\circ}$ any $^{\circ}$ of $^{\circ}$ the $^{\circ}$ phospholipid $^{\circ}$ structures $^{\circ}$ in $^{\circ}$ Figure $^{\circ} 5$. Furthermore, ${ }^{\text {the }}\left[\mathrm{PS}^{\circ}-{ }^{\circ} \mathrm{H}\right]^{-}{ }^{\circ}$ anion ${ }^{\circ}$ shown ${ }^{\circ}{ }^{\circ}$ Figure $^{\circ}{ }^{\circ} \mathrm{j}^{\circ}$ is more stable than other local minima, including zwitterionic isomers, by more than $14 \mathrm{~kJ} \mathrm{~mol}^{-1}$. The additional stabilization of the global minimum may explain why the deprotonation enthalpy of PS is calculated to be $15 \mathrm{~kJ} \mathrm{~mol}^{-1}$ lower than that of PG. This calculated spacing is in good agreement with the difference in deprotonation enthalpies derived from experiment $\left(\Delta \Delta H_{\text {acid }}[\mathrm{PG}-\mathrm{PS}]=13 \mathrm{~kJ} \mathrm{~mol}^{-1}\right)$.

The optimized structures of PI and $[\mathrm{PI}-\mathrm{H}]^{-}$are shown in Figure $5 \mathrm{k}^{\circ}$ and 9, respectively. Both'neutral and anionic structures show an alignment of hydroxyl groups on the inisitol headgroup in order to maximize hydrogen bonding interactions. More importantly, both structures suggest strong interaction between the two of the inisitol hydroxyls and the phosphate moiety. These interactions are particularly significant in the stabilization of $[\mathrm{PI}-\mathrm{H}]^{-}$with simultaneous hydrogen bonds to both charge bearing oxygens (i.e., PO . . H - O $=1.76$ and $1.77 \AA$ ). Only one such charge solvating interaction is present in the optimized structure of $[\mathrm{PG}-\mathrm{H}]^{-}$ (Figure $\left.{ }^{\circ} 5 \mathrm{~h}\right)^{\circ}$ which $^{\circ}$ may $^{\circ} \operatorname{explain}^{\circ}$ why $^{\circ} \mathrm{PI}^{\circ}$ is ${ }^{\circ}$ calculated $^{\circ}$ to be more ${ }^{\circ}$ acidic by ${ }^{\circ}$ about $10 \% \mathrm{~kJ}^{\circ} \mathrm{mol}^{-1^{\circ}}$ (Table 5$)$. The trend of increasing gas phase acidity from PG to PI predicted by theory is consistent with experimental observations, although the difference in deprotonation enthalpies was found experimentally to be much larger $\left(\Delta \Delta H_{\text {acid }}[\mathrm{PG}-\right.$ $\left.\mathrm{PI}]=27 \mathrm{~kJ} \mathrm{~mol}^{-1}\right)$. The calculated deprotonation enthalpy of PI is greater than that of PS, with a difference of just $5 \mathrm{~kJ} \mathrm{~mol}^{-1}$, in contrast to the experimental data which suggests that PI is more acidic than PS by $14 \mathrm{~kJ}$ $\mathrm{mol}^{-1}$.

\section{Comparison of Experiment with Theory}

Overall, the experimental and theoretical determinations of the relative acidity ranking of the five phospholipid classes show a similar trend with the exception of the two most acidic headgroups. Given the size and molecular complexity of the systems examined experimentally and the comparative simplicity of the model systems studied computationally, the agreement in the acidity trends for all but the relative order of PS and PI is pleasing. Experiment and theory suggest that $\mathrm{PE}$ is slightly less acidic than PA, while both are significantly less acidic than PG. Both approaches find PI and PS to<smiles>[R3]OP(=O)(OC)O[CH-][CH]C(C)C</smiles>

Scheme 4. 
Table 5. The enthalpies for the isodesmic reaction shown in Scheme $4\left(\Delta H_{\text {acid }}[\mathrm{PL}]-\Delta H_{\text {acid }}\left[\mathrm{H}_{3} \mathrm{PO}_{4}\right]\right)$ for the different phospholipid ${ }^{\circ}$ classes $^{\circ}$ calculated $^{\circ}$ from $^{\circ}$ the ${ }^{\circ}$ data $^{\circ}$ listed $^{\circ}{ }^{\circ}{ }^{\circ}$ Table $^{\circ} 4$. Deprotonation enthalpies $\left(\Delta H_{\text {acid }}[\mathrm{PL}]\right)$ for the different phospholipid classes are referenced against $\Delta_{\text {acid }} \mathrm{H}_{298}\left[\mathrm{H}_{3} \mathrm{PO}_{4}\right]=$ $1383^{\circ} \pm{ }^{\circ} 21^{\circ} \mathrm{kJ}^{\circ} \mathrm{mol}^{-1^{\circ}}[19]$

\begin{tabular}{lcc}
\hline Phospholipid & $\begin{array}{c}\Delta H_{\text {acid }}\left[\mathrm{H}_{3} \mathrm{PO}_{4}\right]-\Delta H_{\text {acid }}[\mathrm{PL}] \\
\mathrm{kJ} \mathrm{mol}^{-1}\end{array}$ & $\begin{array}{c}\Delta H_{\text {acid }}[\mathrm{PL}] \\
\mathrm{kJ} \mathrm{mol}^{-1}\end{array}$ \\
\hline \hline PE & -7 & 1390 \\
PA & -5 & 1388 \\
PG & 44 & 1339 \\
PS & 59 & 1324 \\
PI & 54 & 1329 \\
\hline
\end{tabular}

be more acidic than PG but differ in the relative ranking of PS and PI. The agreement in the magnitude of the relative deprotonation enthalpies is excellent for PE and PA, with both experiment and theory placing these two species within $2 \mathrm{~kJ} \mathrm{~mol}^{-1}$ of each other. In contrast, theory suggests that PG is more acidic than PA by $49 \mathrm{~kJ}$ $\mathrm{mol}^{-1}$, which is greater than the $23 \mathrm{~kJ} \mathrm{~mol}^{-1}$ derived from the experiment. Experiment finds PS to be $13 \mathrm{~kJ}$ $\mathrm{mol}^{-1}$ more acidic than PG, in good agreement with the $15 \mathrm{~kJ} \mathrm{~mol}^{-1}$ predicted by theory. In contrast, experiment finds PI to be some $27 \mathrm{~kJ} \mathrm{~mol}^{-1}$ more acidic than PG while theory predicts a difference of only $10 \mathrm{~kJ} \mathrm{~mol}^{-1}$. Significantly, this computational finding ranks PI as less acidic than PS in contrast to the direct experimental evidence from the dissociation of the [PS(16:0,16:0)-HPI(16:0,18:2) $]^{-}$dimer, which shows a clear preference for ${ }^{\circ}[\mathrm{PI}(16: 0,18: 2)]^{-}$formation $^{\circ}$ (Table 3 ).

The discrepancies observed between experiment and theory may result from uncertainties within the computational and/or experimental approaches. Recall that in the computational study, the diacyl glycerol portion of phospholipid molecules was modeled as a methyl group, which excludes consideration of certain intra-molecular interactions. Most importantly, interactions between glycerol-fatty acid esters and phospholipid headgroups, which may play a significant role in stabilization of phosphate anions in the gas phase, are not considered. This may be of particular importance for PI where the headgroup is capable of multiple hydrogen bonding interactions and thus model calculations could underestimate the gas phase acidity for this class of phospholipid. Several possible sources of error in the experimental approach must also be considered. (1) The use of [PI(16:0,18:2)-H $]^{-}$instead of $[\mathrm{PI}(16: 0,16: 0)-\mathrm{H}]^{-}$in these studies provides a slight bias toward the formation of the PI anion during the collision induced dissociation of dimers, however, the magnitude of this effect was investigated using the $[\mathrm{PS}(16: 0,16: 0)-\mathrm{H}-\mathrm{PS}(18: 0,18: 0)]^{-}$and [PA(16:0,16:0)-H-PS(16:0,18:1) $]^{-}$dimers and was found to be insufficient to alter the acidity ranking. (2) The assumption of uniform dissociation entropy (assumption 2) and a uniform effective temperature (assumption 3), implicit in the use of eq 2, may not hold for all dimer combinations investigated in this study. Recently, application of the extended kinetic method has been recommended as a means ${ }^{\circ}$ f $^{\circ}$ testing ${ }^{\circ}$ these ${ }^{\circ}$ assumptions ${ }^{\circ}\left[28^{\circ}-30\right]$. This ${ }^{\circ}$ requires the determination of a kinetic method plot for each target compound at a range of excitation energies, usually by variation of the laboratory frame collision energy. In the absence of suitable reference compounds however, a rigorous validation of these assumptions could not be undertaken in the present study. Having said this, the internal consistency ${ }^{\circ}$ of $^{\circ}$ overlapping ${ }^{\circ}$ measurements ${ }^{\circ}\left(\right.$ see $^{\circ}$ Figure $\left.^{\circ} 4\right)$ gives qualitative support to the validity of these assumptions in this case. (3) The observation, in some instances, of fragmentation pathways in competition with direct dissociation of the dimer may imply reverse activation barriers for the primary process and thus a violation of assumption 1. Alternative products were observed for some of the dimers containing PA and other dimers containing PS. These processes are, for the most part, minor and are notably not observed for the dissociation of the [PS(16: 0,16:0)-H-PI(16:0,18:2)] $]^{-}$dimer. The mere observation of such fragments however, must be acknowledged as a potentially serious source of uncertainty in any kinetic method experiment.

Given the number of possible sources of uncertainty discussed above, the overall agreement in the acidity trend between experiment and theory is encouraging. In light of the direct experimental comparison of PI with PS using the kinetic method, we recommend an overall ranking of $\mathrm{PE}<\mathrm{PA} \ll \mathrm{PG}<\mathrm{PS}<\mathrm{PI}$.

\section{Implications for Ionization Efficiency}

The relative gas phase acidities determined in this study show a trend towards increasing acidity of $\mathrm{PE}<\mathrm{PA} \ll$ PG $<$ PS $<$ PI. These data do not match the trend in ionization efficiencies observed in this or previous studies which found PG to be the most readily ionizable species ${ }^{\circ}$ followed ${ }^{\circ} \mathrm{by}^{\circ} \mathrm{PI}^{\circ}>^{\circ} \mathrm{PA}^{\circ} \cong{ }^{\circ} \mathrm{PS}^{\circ}>^{\circ} \mathrm{PE}^{\circ}[11] .^{\circ}$ This suggests that the gas phase acidity of phospholipids have little effect on the process of ion formation during the electrospray process and that other properties, such as surface affinity, may be more critical in determining the relative ionization efficiencies.

\section{Mechanistic Implications for Phospholipid Fragmentation}

Primary fragmentation at the sn-2-position of deprotonated phospholipid anions during collision induced dissociation has been rationalized in terms of two major processes labelled $a_{2}$ and $b_{2}$ in $^{\circ}$ Scheme $^{\circ} 5$ [17]..$^{\circ}$ The analogous mechanisms, $a_{1}$ and $b_{1}$ (not shown), describe the equivalent processes occurring at the sn-1-position. Loss of a neutral fatty acid $\left(\mathrm{R}_{2}{ }^{\prime} \mathrm{CH}_{2} \mathrm{CO}_{2} \mathrm{H}\right)$ is proposed to occur via a nucleophilic attack of the phosphate anion on the glycerol backbone to form a cyclic lysophosphate and displace the carboxylate anion that can abstract an acidic proton from the headgroup to form the $\left[\mathrm{M}-\mathrm{H}-\left(\mathrm{R}_{2}{ }^{\prime} \mathrm{CH}_{2} \mathrm{CO}_{2} \mathrm{H}\right)\right]^{-}$fragment anion (Scheme 5a). Alternatively, the phosphate anion can 


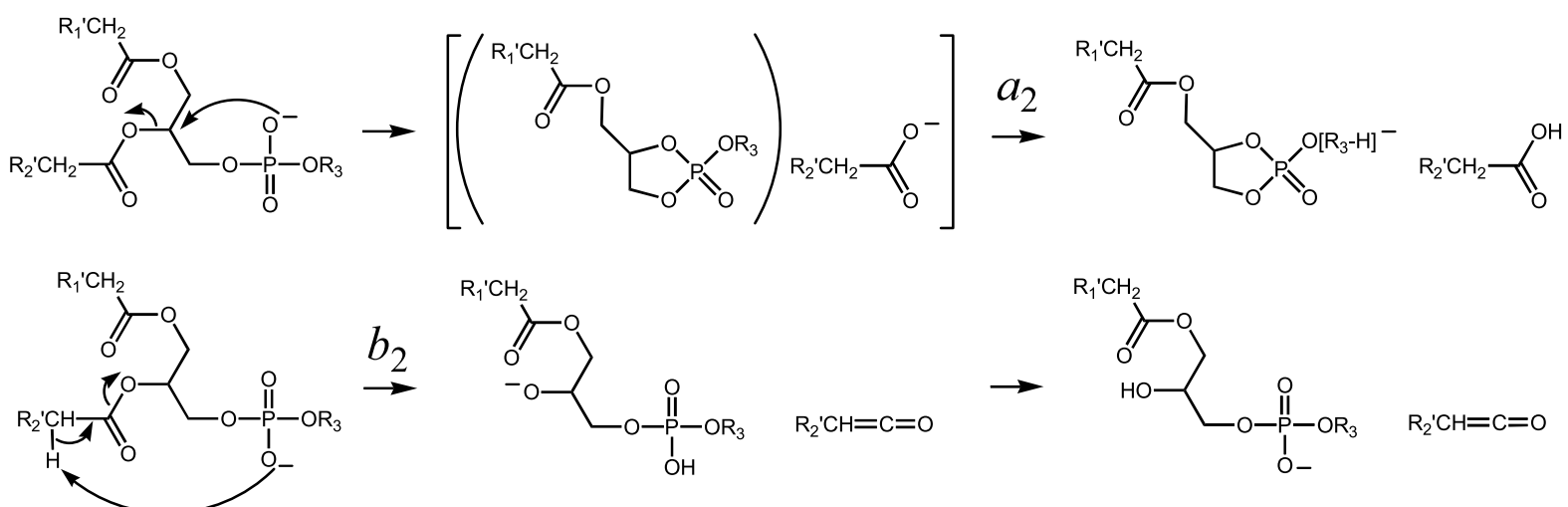

Scheme 5 .

abstract a proton adjacent to the carbonyl in the fatty acid to eliminate the neutral ketene and form the alkoxide anion shown in Scheme $5 \mathbf{b}_{2}$.

These two pathways are competitive processes and the relative abundance of the fragment ions resulting from these two decomposition channels are known to be dependent on the phospholipid head group, $R_{3}$ (Scheme 5). For example, the ESI-MS/MS spectrum of $[\mathrm{PE}-\mathrm{H}]^{-}$shows fragment ion abundances $[\mathrm{M}-\mathrm{H}-$ $\left.\left(\mathrm{R}_{2}{ }^{\prime} \mathrm{CHCO}\right)\right]^{-}>\left[\mathrm{M}-\mathrm{H}-\left(\mathrm{R}_{2}{ }^{\prime} \mathrm{CH}_{2} \mathrm{CO}_{2} \mathrm{H}\right)\right]^{-}$, while conversely, the comparable spectrum for $[\mathrm{PI}-\mathrm{H}]^{-}$ shows $\left[\mathrm{M}-\mathrm{H}-\left(\mathrm{R}_{2}{ }^{\prime} \mathrm{CH}_{2} \mathrm{CO}_{2} \mathrm{H}\right)\right]^{-}>[\mathrm{M}-\mathrm{H}-$ $\left.\left(\mathrm{R}_{2}{ }^{\prime} \mathrm{CHCO}\right)\right]^{-\circ}\left[15,{ }^{\circ} 16\right] .^{\circ}$ There $^{\circ}$ are $^{\circ}$ two $^{\circ}$ possible ${ }^{\circ}$ effects through which the headgroup may influence the outcome of dissociation. (1) The availability of an acidic proton on the headgroup may be important for facile fragmentation via Pathway $a$. In fact, Hsu and Turk have shown that the amine protons in PE do not participate in fragmentation via loss of the fatty acid and have thus postulated an alternative charge remote mechanism to ${ }^{\circ}$ account ${ }^{\circ}$ or ${ }^{9}$ the loss $^{9}[16]$. Such ${ }^{\circ}{ }^{\circ}$ change in mechanism may result in a decrease in the $[\mathrm{M}-\mathrm{H}-$ $\left.\left(\mathrm{R}_{2}{ }^{\prime} \mathrm{CH}_{2} \mathrm{CO}_{2} \mathrm{H}\right)\right]^{-}$ion abundance in the spectrum of [PE $-\mathrm{H}]^{-}$compared with $[\mathrm{PI}-\mathrm{H}]^{-}$. (2) Previous studies have shown that where elimination and nucleophilic substitution reactions compete in the gas phase, increasing the basicity of the reactive anion will increase the $\mathrm{E} 2 / \mathrm{S}_{\mathrm{N}} 2^{\circ}$ ratio $^{\circ}\left[39,{ }^{\circ} 40\right]$. Thus, $^{\circ}$ the ${ }^{\circ}$ decrease ${ }^{\circ}{ }^{\circ}{ }^{\circ} e^{\circ}\left[\mathrm{M}^{\circ}-{ }^{\circ} \mathrm{H}\right.$ $\left.-\left(\mathrm{R}_{2}{ }^{\prime} \mathrm{CH}_{2} \mathrm{CO}_{2} \mathrm{H}\right)\right]^{-}:\left[\mathrm{M}-\mathrm{H}-\left(\mathrm{R}_{2}{ }^{\prime} \mathrm{CHCO}\right)\right]^{-}$ratio for $[\mathrm{PE}-\mathrm{H}]^{-}$compared with $[\mathrm{PI}-\mathrm{H}]^{-}$may also be due to the greater gas phase basicity of the former leading to an increase in ketene elimination (Scheme 5b).

It is difficult to determine the precise contribution of each of the effects discussed above to the observed fragment ion abundances from phospholipid anions. It is interesting to note, however, that the ion abundance ratio $\left[\mathrm{M}-\mathrm{H}-\left(\mathrm{R}_{2}{ }^{\prime} \mathrm{CH}_{2} \mathrm{CO}_{2} \mathrm{H}\right)\right]^{-}:[\mathrm{M}-\mathrm{H}-$ $\left.\left(\mathrm{R}_{2}{ }^{\prime} \mathrm{CHCO}\right)\right]^{-}{ }^{\circ}$ is observed $^{\circ}$ to $^{\circ}$ decrease $^{\circ}$ in $^{\circ}$ the ${ }^{\circ}$ order ${ }^{\circ} \mathrm{PI}^{\circ}>$ $\mathrm{PG}^{\circ}>\mathrm{PE}[15-17]$, ${ }^{\circ}$ which is ${ }^{\circ}$ consistent ${ }^{\circ}$ with the trend for the gas phase acidities obtained in the present study.

* PA is excluded from consideration here due to the presence of a second acidic proton and PS is not considered as it fragments via the corresponding $[\mathrm{PA}-\mathrm{H}]^{-}$anion formed via primary loss of the headgroup.
This observation suggests that the relative basicity of the $[\mathrm{M}-\mathrm{H}]^{-}$anions plays a significant role in influencing the fragmentation pattern resulting from collision induced dissociation.

\section{Conclusions}

Negative ion electrospray ionization of solutions containing equimolar quantities of two dipalmitoyl phospholipids with different headgroups generated a sequence of ionization efficiencies, PE $<$ PS $<$ PA $<$ PG, analogous to that previously observed by Koivusalo et al. ${ }^{\circ}[11] .{ }^{\circ}$ Experimental ${ }^{\circ}$ conditions $^{\circ}$ were $^{\circ}$ established $^{\circ}$ for the observation of proton bound dimers between phospholipids with different headgroups. Collision induced dissociation of these dimers and analysis of the resulting spectra using the kinetic method provides the following acidity sequence for the phospholipid classes: $\mathrm{PE}<\mathrm{PA} \ll \mathrm{PG}<\mathrm{PS}<\mathrm{PI}$. Although several approximations and assumptions are required for this treatment, the internal consistency of the data supports the assignment of this trend. Absolute deprotonation enthalpies were predicted based on electronic structure calculation of the isodesmic proton transfer reaction between model phospholipids and phosphoric acid. The acidity trend obtained from the computational investigation shows general agreement with that obtained experimentally and provides some structural rationale for the relative acidities of the phospholipid classes. The source(s) of the discrepancy between experiment and theory regarding the relative acidity of PI and PS could not be absolutely assigned and thus, some ambiguity remains for these species. However, the direct comparison between these two phospholipids afforded by experiment leads us to recommend an order of acidity of PS < PI. The overall trend in the gas phase acidity of the phospholipid classes, established in this study, does not appear to correlate with the sequence of electrospray ionization efficiencies observed in this or previous work. There does, however, appear to be a relationship between the observed acidities and the fragmentation patterns of deprotonated phospholipids under collision induced dissociation with the less 
acidic (more basic) species favoring elimination over substitution processes.

\section{Acknowledgments}

SJB acknowledges the financial support of the University of Wollongong (URC small grant) and the Institute for Biomolecular Sciences. TWM is supported by a fellowship from the Australian Research Council (ARC-Linkage grant LP0455472). The authors acknowledge the Australian Partnership for Advanced Computing (ANU, Canberra) for a generous allocation of supercomputer time.

\section{References}

1. Gurr, M. I.; Harwood, J. L.; Frayn, K. N. Lipid Biochemistry, 5th ed.; Blackwell Science Ltd.: Oxford, 2002.

2. Daleke, D. L. Regulation of Transbilayer Plasma Membrane Phospholipid Asymmetry. J. Lipid Res. 2003, 44, 233-242.

3. Halliwell, B.; Gutteridge, J. M. C. Free Radicals in Biology and Medicine, 3rd ed.; Oxford University Press: Oxford, 1999.

4. Berridge, M. J. Cell Signaling-a Tale of Two Messengers. Nature 1993, 365, 388-389.

5. Simons, K.; Ikonen, E. Functional Rafts in Cell Membranes. Nature 1997, 387, 569-572.

6. Pike, L. J.; Han, X. L.; Chung, K. N.; Gross, R. W. Lipid Rafts are Enriched in Arachidonic Acid and Plasmenylethanolamine and Their Composition is Independent of Caveolin-1 Expression: A Quantitative Electrospray Ionization/Mass Spectrometric Analysis. Biochemistry 2002, 41, 2075-2088.

7. Pulfer, M.; Murphy, R. C. Electrospray Mass Spectrometry of Phospholipids. Mass Spectrom. Rev. 2003, 22, 332-364.

8. Han, X.; Gross, R. W. Global Analyses of Cellular Lipidomes Directly from Crude Extracts of Biological Samples by ESI Mass Spectrometry: A Bridge to Lipidomics. J. Lipid Res. 2003, 44, 1071-1079.

9. Han, X.; Gross, R. W. Shotgun Lipidomics: Electrospray Ionization Mass Spectrometric Analysis and Quantitation of Cellular Lipidomes Directly from Crude Extracts of Biological Samples. Mass Spectrom. Rev. 2004,

10. Mitchell, T. W.; Turner, N.; Else, P. L.; Hulbert, A. J.; Lee, J. S.; Bruce, C. R.; Hawley, J. A.; Blanksby, S. J. Exercise Alters Phospholipid Molecular Species in Rat Skeletal Muscle. J. Appl. Physiol. 2004, 97, 1823-1829.

11. Koivusalo, M.; Haimi, P.; Heikinheimo, L.; Kostiainen, R.; Somerharju, P. Quantitative Determination of Phospholipid Compositions by ESI-MS: Effects of Acyl Chain Length, Unsaturation, and Lipid Concentration on Instrument Response. J. Lipid Res. 2001, 42, 663-672.

12. Zacarias, A.; Bolanowski, D.; Bhatnagar, A. Comparative Measurements of Multicomponent Phospholipid Mixtures by Electrospray Mass Spectroscopy: Relating Ion Intensity to Concentration. Anal. Biochem. 2002, 308, 152-159.

13. Kebarle, P.; Ho, Y. On the Mechanism of Electrospray Mass Spectrometry. In Electrospray Ionization Mass Spectrometry; Cole, R. B., Ed.; John Wiley and Sons Ltd.: New York, 1997.

14. Marsh, D. CRC Handbook of Lipid Bilayers, 1st ed.; CRC Press: Boca Raton, 1990.

15. Hsu, F. F.; Turk, J. Characterization of Phosphatidylinositol, Phosphatidylinositol-4-Phosphate, and Phosphatidylinositol4,5-Bisphosphate by Electrospray Ionization Tandem Mass Spectrometry: A Mechanistic Study. J. Am. Soc. Mass. Spectrom. 2000, 11, 986-999.

16. Hsu, F. F.; Turk, J. Charge-Remote and Charge-Driven Fragmentation Processes in Diacyl Glycerophosphoethanolamine Upon Low-Energy Collisional Activation: A Mechanistic Proposal. J. Am. Soc. Mass. Spectrom. 2000, 11, 892-899.
17. Hsu, F. F.; Turk, J. Charge-Driven Fragmentation Processes in Diacyl Glycerophosphatidic Acid Upon Low-Energy Collision Activation. A Mechanistic Proposal. J. Am. Soc. Mass. Spectrom. 2000, 11, 797-803.

18. Hsu, F. F.; Turk, J. Studies on Phosphatidylglycerol with Triple Quadrupole Tandem Mass Spectrometry with Electrospray Ionization: Fragmentation Processes and Structural Characterization. J. Am. Soc. Mass. Spectrom. 2001, 12, 10361043.

19. Morris, R. A.; Knighton, W. B.; Viggiano, A. A.; Hoffman, B. C.; Schaefer, H. F. The Gas-Phase Acidity of $\mathrm{H}_{3} \mathrm{PO}_{4}$. J. Chem. Phys. 1997, 106, 3545-3547.

20. Becke, A. D. A New Mixing of Hartree-Fock and Local Density-Functional Theories. J. Chem. Phys. 1993, 98, 13721377.

21. Lee, C. T.; Yang, W. T.; Parr, R. G. Development of the Colle-Salvetti Correlation-Energy Formula into a Functional of the Electron-Density. Phys. Rev. B 1988, 37, 785-789.

22. Frisch, M. J.; Trucks, G. W.; Schlegel, H. B.; Scuseria, G. E.; Robb, M. A.; Cheeseman, J. R.; Montgomery, J. A., Jr.; Vreven, T.; Kudin, K. N.; Burant, J. C.; Millam, J. M.; Iyengar, S. S.; Tomasi, J.; Barone, V.; Mennucci, B.; Cossi, M.; Scalmani, G.; Rega, N.; Petersson, G. A.; Nakatsuji, H.; Hada, M.; Ehara, M.; Toyota, K.; Fukuda, R.; Hasegawa, J.; Ishida, M.; Nakajima, T.; Honda, Y.; Kitao, O.; Nakai, H.; Klene, M.; Li, X.; Knox, J. E.; Hratchian, H. P.; Cross, J. B.; Bakken, V.; Adamo, C.; Jaramillo, J.; Gomperts, R.; Stratmann, R. E.; Yazyev, O.; Austin, A. J.; Cammi, R.; Pomelli, C.; Ochterski, J. W.; Ayala, P. Y.; Morokuma, K.; Voth, G. A.; Salvador, P.; Dannenberg, J. J.; Zakrzewski, V. G.; Dapprich, S.; Daniels, A. D.; Strain, M. C.; Farkas, O.; Malick, D. K.; Rabuck, A. D.; Raghavachari, K.; Foresman, J. B.; Ortiz, J. V.; Cui, Q.; Baboul, A. G.; Clifford, S.; Cioslowski, J.; Stefanov, B. B.; Liu, G.; Liashenko, A.; Piskorz, P.; Komaromi, I.; Martin, R. L.; Fox, D. J.; Keith, T.; Al-Laham, M. A.; Peng, C. Y.; Nanayakkara, A.; Challacombe, M.; Gill, P. M. W.; Johnson, B.; Chen, W.; Wong, M. W.; Gonzalez, C.; Pople, J. A.; Gaussian 03, Revision C.02; Gaussian Inc: Wallingford, CT, 2004.

23. Foresman, J. B.; Frisch, A. Exploring Chemistry with Electronic Structure Methods, 2nd ed.; Gaussian Inc.: Pittsburgh, PA, 1996.

24. Hanson, C. L.; Ilag, L. L.; Malo, J.; Hatters, D. M.; Howlett, G. J.; Robinson, C. V. Phospholipid Complexation and Association with Apolipoprotein C-II: Insights from Mass Spectrometry. Biophys. J. 2003, 85, 3802-3812.

25. Strittmatter, E. F.; Schnier, P. D.; Klassen, J. S.; Williams, E. R. Dissociation Energies of Deoxyribose Nucleotide Dimer Anions Measured Using Blackbody Infrared Radiative Dissociation. J. Am. Soc. Mass. Spectrom. 1999, 10, 1095-1104.

26. Cooks, R. G.; Kruger, T. L. Intrinsic Basicity Determination Using Metastable Ions. J. Am. Chem. Soc. 1977, 99, 1279-1280.

27. Bouchoux, G.; Sablier, M.; Berruyer-Penaud, F. Obtaining Thermochemical Data by the Extended Kinetic Method. J. Mass Spectrom. 2004, 39, 986-997.

28. Drahos, L.; Peltz, C.; Vekey, K. Accuracy of Enthalpy and Entropy Determination Using the Kinetic Method: Are We Approaching a Consensus? J. Mass Spectrom. 2004, 39, 1016-1024.

29. Ervin, K. M.; Armentrout, P. B. Systematic and Random Errors in Ion Affinities and Activation Entropies from the Extended Kinetic Method. J. Mass Spectrom. 2004, 39, 1004-1015.

30. Drahos, L.; Vekey, K. Entropy Evaluation Using the Kinetic Method: Is It Feasible? J. Mass Spectrom. 2003, 38, 1025-1042.

31. Ervin, K. M. Microcanonical Analysis of the Kinetic Method. The Meaning of the "Apparent Entropy". J. Am. Soc. Mass. Spectrom. 2002, 13, 435-452. 
32. Ervin, K. M. Microcanonical Analysis of the Kinetic Method: The Meaning of the "Effective Temperature". Int. J. Mass Spectrom. 2000, 195/196, 271-284.

33. Cooks, R. G.; Koskinen, J. T.; Thomas, P. D. Special Feature: Commentary-the Kinetic Method of Making Thermochemical Determinations. J. Mass Spectrom. 1999, 34, 85-92.

34. Drahos, L.; Vekey, K. Special Feature: Commentary-How Closely Related are the Effective and the Real Temperature. J. Mass Spectrom. 1999, 34, 79-84.

35. Armentrout, P. B. Special Feature: Commentary-Is the Kinetic Method a Thermodynamic Method? J. Mass Spectrom. 1999, 34, 74-78.

36. Bianciotto, M.; Barthelat, J. C.; Vigroux, A. Reactivity of Phosphate Monoester Monoanions in Aqueous Solution. 1.
Quantum Mechanical Calculations Support the Existence of "Anionic Zwitterion" $\mathrm{MeO}^{+}(\mathrm{H}) \mathrm{PO}_{3}^{2-}$ as a Key Intermediate in the Dissociative Hydrolysis of the Methyl Phosphate Anion. J. Am. Chem. Soc. 2002, 124, 7573-7587.

37. Bondi, A. Van Der Waals Volumes and Radii. J. Phys. Chem. 1964, 68, 441-451.

38. Landin, J.; Pascher, I.; Cremer, D. Effect of a Polar Environment on the Conformation of Phospholipid Head Groups Analyzed with the Onsager Continuum Solvation Model. J. Phys. Chem. A 1997, 101, 2996-3004.

39. Flores, A. E.; Gronert, S. The Gas-Phase Reactions of Dianions with Alkyl Bromides: Direct Identification of $\mathrm{S}_{\mathrm{N}} 2$ and E2 Products. J. Am. Chem. Soc. 1999, 121, 2627-2628.

40. Gronert, S. Mass Spectrometric Studies of Organic Ion/Molecule Reactions. Chem. Rev. 2001, 101, 329-360. 


\section{Appendices}

\begin{tabular}{rcrc}
\hline $\mathrm{H}_{3} \mathrm{PO}_{4}$ atom & $x$ & $y$ & \multicolumn{1}{c}{$\mathrm{z}$} \\
\hline \hline 8 & -0.000021 & -0.000025 & 1.60138 \\
15 & -0.000021 & -0.000025 & 0.11905 \\
8 & -1.315048 & -0.597714 & -0.595422 \\
8 & 1.17524 & -0.840019 & -0.595324 \\
8 & 0.139992 & 1.437678 & -0.595375 \\
1 & -0.324614 & 2.135203 & -0.10307 \\
1 & -1.687771 & -1.347689 & -0.102107 \\
1 & 2.011406 & -0.786501 & -0.10265 \\
& & & \\
\hline
\end{tabular}

\begin{tabular}{rcrr}
\hline $\mathrm{H}_{2} \mathrm{PO}_{4}{ }^{-}$atom & $\mathrm{x}$ & $\mathrm{y}$ & \multicolumn{1}{c}{$\mathrm{z}$} \\
\hline \hline 8 & 0.19467 & -0.852984 & 1.291808 \\
15 & -0.019818 & 0.109921 & 0.136641 \\
8 & -1.236834 & -0.560913 & -0.810301 \\
8 & 1.321596 & -0.077829 & -0.864051 \\
8 & -0.302081 & 1.576157 & 0.255107 \\
1 & -1.3244 & -1.481563 & -0.518096 \\
1 & 1.802859 & -0.842702 & -0.512022 \\
\hline
\end{tabular}

\begin{tabular}{rccc}
\hline PA atom & $\mathrm{x}$ & $\mathrm{y}$ & $\mathrm{z}$ \\
\hline \hline 6 & -2.23214 & 0.032664 & -0.023401 \\
8 & -0.975002 & 0.743273 & 0.00755 \\
15 & 0.40771 & -0.062259 & -0.12003 \\
8 & 1.465813 & 1.147168 & -0.060897 \\
8 & 0.479502 & -0.798698 & 1.332304 \\
8 & 0.61172 & -0.973942 & -1.264369 \\
1 & 1.275172 & 1.794611 & 0.638891 \\
1 & 0.984295 & -1.627621 & 1.27501 \\
1 & -3.007721 & 0.799262 & -0.010504 \\
1 & -2.307426 & -0.562353 & -0.937867 \\
1 & -2.323389 & -0.608393 & 0.858614 \\
\hline PA-H $^{-}$atom & $\mathrm{x}$ & $\mathrm{y}$ & $\mathrm{z}$ \\
\hline \hline 6 & 2.195732 & -0.106421 & -0.024066 \\
8 & 0.964694 & -0.576404 & -0.540311 \\
15 & -0.422727 & 0.13626 & 0.104598 \\
8 & -0.391337 & 1.607505 & -0.20585 \\
8 & -1.512968 & -0.61377 & -0.911155 \\
8 & -0.638327 & -0.419315 & 1.496073 \\
1 & -1.802451 & -1.414458 & -0.446379 \\
1 & 2.997572 & -0.642517 & -0.548675 \\
1 & 2.313016 & 0.973529 & -0.194826 \\
1 & 2.281884 & -0.30606 & 1.05525 \\
\hline PE atom & & & \\
\hline
\end{tabular}

\begin{tabular}{rccc}
\hline PE atom & $x$ & $y$ & $z$ \\
\hline \hline 6 & -2.395947 & 1.4791 & -0.471385 \\
8 & -1.147177 & 0.798709 & -0.69877 \\
15 & -0.790377 & -0.507139 & 0.205953 \\
8 & -0.206371 & 0.066315 & 1.58206 \\
8 & -1.885678 & -1.482185 & 0.374171 \\
8 & 0.479232 & -1.08006 & -0.617773 \\
6 & 1.515831 & -0.286879 & -1.21854 \\
6 & 2.668346 & -0.006273 & -0.258024 \\
7 & 2.278588 & 0.943289 & 0.807028 \\
1 & -2.472023 & 2.242835 & -1.247897 \\
1 & -3.230343 & 0.776675 & -0.550895 \\
1 & -2.399962 & 1.952379 & 0.516764 \\
1 & 1.887043 & -0.884027 & -2.056716 \\
1 & 1.090061 & 0.641181 & -1.617609 \\
1 & 3.525759 & 0.355182 & -0.847251 \\
1 & 2.963806 & -0.944914 & 0.22172
\end{tabular}

\begin{tabular}{|c|c|c|c|}
\hline $\mathrm{PE}$ atom & $x$ & $y$ & $z$ \\
\hline 1 & 2.19063 & 1.888267 & 0.433292 \\
\hline 1 & 2.989201 & 0.979849 & 1.536028 \\
\hline 1 & 0.711935 & 0.458708 & 1.444264 \\
\hline$[\mathrm{PE}-\mathrm{H}]^{-}$atom & $x$ & y & z \\
\hline 6 & 2.499589 & -1.428707 & -0.26335 \\
\hline 8 & 1.483899 & -0.60301 & -0.805363 \\
\hline 15 & 0.761394 & 0.492075 & 0.251435 \\
\hline 8 & 0.244796 & -0.301337 & 1.436072 \\
\hline 8 & 1.627736 & 1.706658 & 0.409991 \\
\hline 8 & -0.497578 & 0.913312 & -0.745583 \\
\hline 6 & -1.475671 & -0.028191 & -1.179257 \\
\hline 6 & -2.740504 & -0.023808 & -0.306282 \\
\hline 7 & -2.659244 & -0.702526 & 0.991704 \\
\hline 1 & 2.816776 & -2.118509 & -1.055957 \\
\hline 1 & 3.369143 & -0.835299 & 0.057409 \\
\hline 1 & 2.127736 & -2.004147 & 0.595604 \\
\hline 1 & -1.747983 & 0.273978 & -2.202866 \\
\hline 1 & -1.045452 & -1.038557 & -1.230244 \\
\hline 1 & -3.557651 & -0.48354 & -0.885903 \\
\hline 1 & -3.023222 & 1.023608 & -0.133201 \\
\hline 1 & -1.782099 & -0.419462 & 1.447228 \\
\hline 1 & -2.534762 & -1.702252 & 0.826881 \\
\hline PG atom & $x$ & y & z \\
\hline 6 & -3.455307 & 0.166318 & 0.943821 \\
\hline 8 & -2.417652 & -0.60837 & 0.305383 \\
\hline 15 & -1.182193 & 0.144399 & -0.393519 \\
\hline 8 & 0.007139 & 0.224584 & 0.731009 \\
\hline 6 & 0.816123 & -0.914802 & 1.087576 \\
\hline 6 & 2.171524 & -0.823001 & 0.386369 \\
\hline 6 & 2.932548 & 0.479822 & 0.708289 \\
\hline 8 & 2.48765 & 1.549954 & -0.120391 \\
\hline 8 & -0.715437 & -1.006799 & -1.398319 \\
\hline 8 & -1.46199 & 1.506756 & -0.898468 \\
\hline 8 & 1.997507 & -0.913279 & -1.039477 \\
\hline 1 & 0.272152 & -1.059976 & -1.483015 \\
\hline 1 & -4.268149 & -0.533904 & 1.142122 \\
\hline 1 & -3.08859 & 0.587547 & 1.885651 \\
\hline 1 & -3.793889 & 0.968339 & 0.28361 \\
\hline 1 & 0.952988 & -0.879301 & 2.173691 \\
\hline 1 & 0.305082 & -1.848806 & 0.832506 \\
\hline 1 & 2.772749 & -1.684895 & 0.706286 \\
\hline 1 & 2.217913 & -0.026292 & -1.392333 \\
\hline 1 & 3.994342 & 0.357017 & 0.476147 \\
\hline 1 & 2.837868 & 0.723973 & 1.774863 \\
\hline 1 & 1.563375 & 1.757522 & 0.109027 \\
\hline$[\mathrm{PG}-\mathrm{H}]^{-}$atom & $x$ & $y$ & $z$ \\
\hline 6 & -3.122913 & 0.14157 & 1.225898 \\
\hline 8 & -2.291084 & -0.688384 & 0.423655 \\
\hline 15 & -1.197087 & 0.05677 & -0.585442 \\
\hline 8 & -1.769697 & 1.332197 & -1.121988 \\
\hline 8 & -0.019516 & 0.519906 & 0.535625 \\
\hline 6 & 0.755591 & -0.49815 & 1.188522 \\
\hline 6 & 2.120147 & -0.732752 & 0.523323 \\
\hline 8 & 2.032389 & -1.37155 & -0.733832 \\
\hline 8 & -0.597373 & -1.052701 & -1.417322 \\
\hline 6 & 2.970475 & 0.549874 & 0.4649 \\
\hline 8 & 2.420629 & 1.617772 & -0.290816 \\
\hline 1 & -3.826482 & -0.519806 & 1.745149 \\
\hline 1 & -2.533203 & 0.695342 & 1.970828 \\
\hline 1 & -3.673302 & 0.861323 & 0.608993 \\
\hline 1 & 0.919246 & -0.148269 & 2.217576 \\
\hline
\end{tabular}




\begin{tabular}{|c|c|c|c|c|c|c|c|c|}
\hline$[\mathrm{PG}-\mathrm{H}]^{-}$atom & $x$ & $y$ & $z$ & PS (zwitt & atom & $x$ & $y$ & $z$ \\
\hline 1 & 0.19509 & -1.439652 & 1.228157 & 8 & & 2.538487 & -1.865159 & 0.401058 \\
\hline 1 & 2.665876 & -1.416283 & 1.202448 & 7 & & 1.861883 & 1.585552 & -0.355673 \\
\hline 1 & 1.114886 & -1.26672 & -1.101657 & 8 & & 1.729660 & -0.716660 & -1.404247 \\
\hline 1 & 3.936158 & 0.303559 & 0.006741 & 1 & & -2.811422 & -1.668620 & 1.167279 \\
\hline 1 & 3.16561 & 0.874421 & 1.506474 & 1 & & -3.213195 & -1.695824 & -0.582659 \\
\hline 1 & 1.44984 & 1.583353 & -0.181502 & 1 & & -4.351788 & -0.958799 & 0.590692 \\
\hline & & & & 1 & & 0.015196 & -0.789508 & -1.562876 \\
\hline PS atom & $x$ & $y$ & $\mathrm{z}$ & 1 & & 0.532322 & 1.338368 & 2.007450 \\
\hline 6 & 3.805843 & -1.213101 & 0.066236 & 1 & & 1.106164 & -0.298149 & 2.429903 \\
\hline 8 & 3.018967 & -0.188148 & -0.574392 & 1 & & 2.918559 & 0.626315 & 1.230142 \\
\hline 15 & 1.665742 & 0.308991 & 0.112022 & 1 & & 0.896706 & 1.998502 & -0.342198 \\
\hline 8 & 0.564557 & -0.766267 & -0.459636 & 1 & & 1.928552 & 1.062640 & -1.267437 \\
\hline 6 & -0.713243 & -0.882399 & 0.169391 & 1 & & 2.580024 & 2.306672 & -0.275667 \\
\hline 6 & -1.729328 & 0.091317 & -0.469877 & $\overline{[P S-H]^{-}}$ & rion) atom & $x$ & $y$ & z \\
\hline 7 & -1.347623 & 1.487364 & -0.234722 & & & & & \\
\hline 8 & 1.642205 & 0.386844 & 1.596059 & 6 & & 2.924130 & 1.701600 & -0.684404 \\
\hline 8 & 1.396554 & 1.644954 & -0.716194 & 8 & & 1.982423 & 0.741764 & -1.060616 \\
\hline 6 & -3.14225 & -0.218304 & 0.032056 & 15 & & 1.785883 & -0.501338 & 0.121242 \\
\hline 8 & -3.822934 & 0.533765 & 0.694887 & 8 & & 1.099245 & -1.692073 & -0.644292 \\
\hline 8 & -3.5549 & -1.447717 & -0.354022 & 8 & & 3.056899 & -0.601424 & 1.018092 \\
\hline 1 & 4.749438 & -1.246919 & -0.480179 & 8 & & 0.545592 & 0.237740 & 1.089244 \\
\hline 1 & 3.983025 & -0.961716 & 1.115294 & 6 & & -0.561490 & 0.730742 & 0.395088 \\
\hline 1 & 3.297433 & -2.17965 & -0.009902 & 6 & & -1.745665 & -0.241983 & 0.484598 \\
\hline 1 & -1.044844 & -1.909618 & 0.006967 & 7 & & -1.483856 & -1.496945 & -0.273754 \\
\hline 1 & -0.621079 & -0.697994 & 1.246793 & 6 & & -3.089271 & 0.419660 & -0.012790 \\
\hline 1 & -1.712068 & -0.090463 & -1.551085 & 8 & & -3.312644 & 1.592305 & 0.353070 \\
\hline 1 & -1.976201 & 2.110509 & -0.740566 & 8 & & -3.840597 & -0.322849 & -0.707828 \\
\hline 1 & -1.467705 & 1.718835 & 0.752989 & 1 & & 2.410408 & 2.544655 & -0.153414 \\
\hline 1 & 0.412538 & 1.823221 & -0.657236 & 1 & & 3.719870 & 1.270369 & -0.021569 \\
\hline 1 & -4.455029 & -1.58514 & -0.000808 & 1 & & 3.384224 & 2.080783 & -1.634062 \\
\hline$[\mathrm{PS}-\mathrm{H}]^{-}$atom & $x$ & $\mathrm{y}$ & $z$ & $\begin{array}{l}1 \\
1\end{array}$ & & $\begin{array}{l}-0.316398 \\
-1.900314\end{array}$ & $\begin{array}{r}0.970976 \\
-0.523815\end{array}$ & $\begin{array}{r}-0.674532 \\
1.564267\end{array}$ \\
\hline 6 & 3.50267 & -0.051954 & 1.117748 & 1 & & -2.384530 & -1.858273 & -0.613869 \\
\hline 8 & 2.59681 & -0.794654 & 0.307325 & 1 & & -0.857744 & -1.291402 & -1.070683 \\
\hline 15 & 1.402134 & 0.020011 & -0.473172 & 1 & & -0.988046 & -2.174197 & 0.305644 \\
\hline 8 & 0.421299 & 0.30522 & 0.852189 & 1 & & -0.882293 & 1.675753 & 0.919555 \\
\hline 6 & -0.692453 & 1.176811 & 0.697387 & PI atom & $x$ & & $y$ & $z$ \\
\hline 6 & -1.800262 & 0.642584 & -0.245921 & म & n & & $y$ & 2 \\
\hline 7 & -2.905081 & 1.610066 & -0.218955 & 6 & -0.080344 & -0.02 & 28268 & -0.880247 \\
\hline 8 & 1.895914 & 1.320669 & -1.038824 & 6 & -0.665813 & & 63163 & -0.095897 \\
\hline 8 & 0.676705 & -1.004671 & -1.335962 & 6 & -2.186237 & 1.18 & 81227 & -0.300757 \\
\hline 6 & -2.265761 & -0.777845 & 0.155023 & 6 & -2.809174 & -0.11 & 1438 & 0.208022 \\
\hline 8 & -3.293189 & -0.935765 & 0.806402 & 6 & -2.222172 & -1.32 & 23592 & -0.520224 \\
\hline 8 & -1.531611 & -1.802134 & -0.24427 & 6 & -0.691159 & -1.36 & 62419 & -0.432943 \\
\hline 1 & 4.294221 & -0.745189 & 1.422801 & 8 & -0.174175 & 2.4 & 10643 & -0.546715 \\
\hline 1 & 3.935892 & 0.784844 & 0.557542 & 8 & -2.785429 & 2.24 & 46581 & 0.423737 \\
\hline 1 & 2.996992 & 0.335694 & 2.012345 & 8 & -4.218161 & -0.16 & 64031 & -0.007371 \\
\hline 1 & -1.116367 & 1.312294 & 1.699807 & 8 & -2.682102 & -2.5 & 45917 & 0.056144 \\
\hline 1 & -1.388574 & 0.604901 & -1.259364 & 8 & -0.290693 & -1.62 & 27596 & 0.921953 \\
\hline 1 & -3.535048 & 1.331588 & 0.535212 & 8 & 1.361103 & -0.12 & 25438 & -0.86396 \\
\hline 1 & -3.45054 & 1.521484 & -1.074591 & 15 & 2.363123 & 0.33 & 36467 & 0.329616 \\
\hline 1 & -0.65324 & -1.515583 & -0.697457 & 8 & 2.278514 & -0.83 & 37707 & 1.420512 \\
\hline 1 & -0.372362 & 2.152452 & 0.313676 & 8 & 3.798153 & 0.15 & 54758 & -0.332102 \\
\hline PS (zwitterion & ) atom & $\mathrm{V}$ & 7 & 6 & 4.286922 & -1.11 & 19656 & -0.797841 \\
\hline 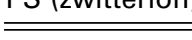 & I dorm & $y$ & Z & 8 & 2.136939 & 1.72 & 23477 & 0.813086 \\
\hline 6 & -3.302981 & $1-1.134107$ & 0.349693 & 1 & -0.31656 & 0.11 & 16196 & -1.940271 \\
\hline 8 & -2.717103 & 0.181635 & 0.194986 & 1 & -0.314093 & -2.16 & 66463 & -1.078328 \\
\hline 15 & -1.191990 & 0.383953 & -0.187741 & 1 & -2.518636 & -1.27 & 75811 & -1.578796 \\
\hline 8 & -0.962416 & $6-0.596872$ & -1.416555 & 1 & -2.598121 & $-0.2 C$ & 00194 & 1.283648 \\
\hline 8 & -0.835376 & $6 \quad 1.827572$ & -0.371711 & 1 & -2.403575 & 1.25 & 99573 & -1.375175 \\
\hline 8 & -0.337346 & $6-0.279325$ & 1.025217 & 1 & -0.463781 & 1.0 & 4596 & 0.976369 \\
\hline 6 & 0.816353 & 0.357752 & 1.607852 & 1 & -0.865247 & -2.3 & 41391 & 1.254461 \\
\hline 6 & 2.008908 & 0.453764 & 0.650718 & 1 & -3.644434 & -2.47 & 70405 & 0.176944 \\
\hline 6 & 2.130770 & $0-0.875622$ & -0.194730 & 1 & -4.606896 & 0.63 & 37172 & 0.382595 \\
\hline
\end{tabular}




\begin{tabular}{lccr}
\hline $\mathrm{Pl}$ atom & $\mathrm{x}$ & $\mathrm{y}$ & $\mathrm{z}$ \\
\hline \hline 1 & -2.258207 & 3.044802 & 0.241409 \\
1 & 0.707423 & 2.530269 & -0.128973 \\
1 & 1.384317 & -1.260202 & 1.428942 \\
1 & 5.311929 & -0.940469 & -1.125132 \\
1 & 4.27224 & -1.851196 & 0.014351 \\
1 & 3.681478 & -1.46945 & -1.63922 \\
\hline$[\mathrm{PI}-\mathrm{H}]^{-}$atom & $\mathrm{x}$ & $\mathrm{y}$ & $\mathrm{z}$ \\
\hline \hline 6 & -0.061838 & -0.089831 & -0.856827 \\
6 & -0.625422 & 1.132004 & -0.102414 \\
6 & -2.145372 & 1.155135 & -0.266536 \\
6 & -2.778452 & -0.13262 & 0.244319 \\
6 & -2.18772 & -1.33933 & -0.486947 \\
6 & -0.665187 & -1.398133 & -0.278506 \\
8 & -0.14134 & 2.377077 & -0.585873 \\
8 & -2.719566 & 2.254855 & 0.448484 \\
8 & -4.199521 & -0.143328 & 0.008514 \\
8 & -2.800385 & -2.553887 & -0.063114 \\
8 & -0.397527 & -1.578719 & 1.095937 \\
8 & 1.364516 & -0.138792 & -0.923056
\end{tabular}

\begin{tabular}{cccc}
\hline$[\mathrm{PI}-\mathrm{H}]^{-}$atom & $\mathrm{x}$ & $\mathrm{y}$ & $\mathrm{z}$ \\
\hline \hline 15 & 2.371989 & 0.33296 & 0.325249 \\
8 & 2.135051 & -0.608971 & 1.489698 \\
8 & 3.801448 & -0.010177 & -0.400177 \\
6 & 4.181751 & -1.375268 & -0.556569 \\
8 & 2.290331 & 1.833229 & 0.479924 \\
1 & -0.370837 & -0.008906 & -1.908373 \\
1 & -0.268439 & -2.242353 & -0.867687 \\
1 & -2.374988 & -1.207816 & -1.566725 \\
1 & -2.586719 & -0.23595 & 1.31899 \\
1 & -2.383433 & 1.271046 & -1.337036 \\
1 & -0.392189 & 1.037484 & 0.966327 \\
1 & 0.548272 & -1.341271 & 1.289323 \\
1 & -3.750753 & -2.364735 & 0.012703 \\
1 & -4.552742 & 0.673399 & 0.397643 \\
1 & -2.097205 & 2.994035 & 0.318918 \\
1 & 0.800846 & 2.428393 & -0.270124 \\
1 & 5.223663 & -1.374119 & -0.894323 \\
1 & 4.097672 & -1.917102 & 0.392087 \\
1 & 3.55638 & -1.868536 & -1.312275 \\
\hline
\end{tabular}

